University of Wollongong

Research Online

Faculty of Engineering and Information

Faculty of Engineering and Information

Sciences - Papers: Part A

Sciences

$1-1-2015$

\title{
Numerical simulations of response of tubular steel beams to close-range explosions
}

Tuan D. Ngo

University of Melbourne

Damith Mohotti

University of Melbourne

Alex M. Remennikov

University of Wollongong, alexrem@uow.edu.au

Brian Uy

University of New South Wales, brianuy@uow.edu.au

Follow this and additional works at: https://ro.uow.edu.au/eispapers

Part of the Engineering Commons, and the Science and Technology Studies Commons

Research Online is the open access institutional repository for the University of Wollongong. For further information contact the UOW Library: research-pubs@uow.edu.au 


\title{
Numerical simulations of response of tubular steel beams to close-range explosions
}

\author{
Abstract \\ A numerical study of hollow and concrete-filled square tubular steel columns subjected to near-field \\ detonations has been undertaken and validated through the experimental results. The experiments used \\ concrete-filled and hollow square tubular columns ( $100 \times 5 \mathrm{~mm}$ SHS Grade C350) made out of cold- \\ formed structural steel hollow sections (SHS) that were simply supported at both ends. High explosives \\ TNT charges were placed above the top surface of the column at two different scaled standoff distances \\ of $0.12 \mathrm{~m} / \mathrm{kg} 1 / 3$ and $0.15 \mathrm{~m} / \mathrm{kg} 1 / 3$. Failure patterns and permanent mid-span deformations were \\ recorded and compared with the numerical analysis results. Arbitrary Lagrangian-Eulerian (ALE) \\ formulations coupled with fluid-structure interaction (FSI) algorithms that are available in the advanced \\ finite element code LS-DYNA were used in the numerical study. A detailed description of the numerical \\ technique adopted in the study is presented. The models were validated with the experimental results and \\ were used to obtain the failure pattern, permanent plastic deformation, pressure and impulse time \\ histories, stress distribution, and energy absorption of the different configurations of the columns. The \\ performance of hollow and concrete-filled SHS tubes for blast load mitigation was assessed and \\ discussed.

\section{Keywords} \\ Close-range detonation, steel hollow sections (SHS), Arbitrary Lagrangian-Eulerian (ALE), LS-DYNA

\section{Disciplines} \\ Engineering | Science and Technology Studies

\section{Publication Details} \\ Ngo, T. D., Mohotti, D., Remennikov, A. \& Uy, B. (2015). Numerical simulations of response of tubular steel \\ beams to close-range explosions. Journal of Constructional Steel Research, 105 151-163.
}


${ }^{\dagger a}$ Tuan Ngo, ${ }^{\mathrm{a}}$ Damith Mohotti, ${ }^{\mathrm{b}}$ Alex Remennikov, ${ }^{\mathrm{c}}$ Brian Uy

${ }^{\dagger a}$ Department of Infrastructure Engineering, The University of Melbourne, Victoria 3010, Australia

${ }^{b}$ Centre for Infrastructure Protection and Mining Safety, School of Civil, Mining \& Environmental Engineering, University of Wollongong, NSW, Australia

${ }^{c}$ Centre for Infrastructure Engineering, School of Civil and Environmental Engineering, The University of New South Wales, NSW, Australia

\author{
${ }^{\dagger}$ Corresponding author: \\ Dr. Tuan Ngo \\ †a Department of Infrastructure Engineering, The University of Melbourne, \\ Victoria 3010, Australia \\ Email: dtngo@unimelb.edu.au \\ Tel.: +61 411987732
}




\title{
NUMERICAL SIMULATIONS OF RESPONSE OF TUBULAR STEEL COLUMNS TO CLOSE-RANGE EXPLOSIONS
}

\author{
$\dagger^{\mathrm{a}}$ Tuan Ngo, ${ }^{\mathrm{a}}$ Damith Mohotti, ${ }^{\mathrm{b}}$ Alex Remennikov, ${ }^{\mathrm{c}}$ Brian Uy \\ ${ }^{\dagger}$ Department of Infrastructure Engineering, The University of Melbourne, \\ Victoria 3010, Australia \\ ${ }^{b}$ Centre for Infrastructure Protection and Mining Safety, School of Civil, Mining \& \\ Environmental Engineering, University of Wollongong, NSW, Australia \\ ${ }^{c}$ Centre for Infrastructure Engineering, School of Civil and Environmental Engineering, \\ The University of New South Wales, NSW, Australia
}

\begin{abstract}
A numerical study of hollow and concrete-filled square tubular steel columns subjected to near-field detonations has been undertaken and validated through the experimental results. The experiments used concrete-filled and hollow square tubular columns (100 x $5 \mathrm{~mm}$ SHS Grade C350) made out of cold-formed structural steel hollow sections (SHS) that were simply supported at both ends. High explosives TNT charges were placed above the top surface of the column at two different scaled stand-off distances of $0.12 \mathrm{~m} / \mathrm{kg}^{1 / 3}$ and $0.15 \mathrm{~m} / \mathrm{kg}^{1 / 3}$. Failure patterns and permanent mid-span deformations were recorded and compared with the numerical analysis results. Arbitrary Lagrangian-Eulerian (ALE) formulations coupled with fluid-structure interaction (FSI) algorithms that are available in the advanced finite element code LS-DYNA were used in the numerical study. A detailed description of the numerical technique adopted in the study is presented. The models were validated with the experimental results and were used to obtain the failure pattern, permanent plastic deformation, pressure and impulse time histories, stress distribution, and energy absorption of the different configurations of the columns. The performance of hollow and concrete-filled SHS tubes for blast load mitigation were assessed and discussed.
\end{abstract}

Keywords: Near-field detonation, steel hollow sections (SHS), Arbitrary LagrangianEulerian (ALE), LS-DYNA. 


\subsection{Introduction}

The response of structural systems and elements subjected to far-field explosions have been broadly investigated both experimentally and numerically. However, the response of structures subjected to near-field detonations has received less focus within the research community. The near-field region is defined here as the region within 15-20 radii (for equivalent spherical blast source) of the face of the explosive within which the blast loading is affected by local phenomena (e.g., expansion of detonation products, afterburn) that are not observed in the far field blast loading regime. Therefore the mechanism of near-field detonation and blast loading is more complex than that for far-field detonation. There is a possibility of key elements of structures being subjected to close-in blast loading, such as those resulting from explosives attached to critical elements of a structure, backpack and suitcases explosive threats, and vehicle or parcel bombs targeting key structural elements of buildings and bridges. Therefore, understanding the structural behaviour and damage mechanisms of these structural members is very important in blast vulnerability assessment and in the design of protective structures.

The effect of a blast wave on a structure is primarily dependent on the released energy and the distance from the source of the explosion. However, more detailed information such as the pressure, impulse and duration are required to predict the impact of the blast wave. Furthermore, an increasing amount of energy leads to higher pressures and a greater specific impulse. An increasing distance to the target leads to a decrease in pressure and impulse but an increase in blast duration [1]. Kingery and Bulmash [2] were the first to compile, analyse and present the air blast parameters associated with TNT spherical free-air bursts based on experimental results obtained from the detonation of $1 \mathrm{~kg}$ to $4 \times 10^{6} \mathrm{~kg}$ charges. The parameters were processed through a curve fitting technique and presented via polynomial functions, which were the basis of the procedure found in TM5-1300 (superseded by the UFC 
3-340-02) that describes structural behaviour under blast loads [3]. The relationships developed by Kingery and Bulmash [2] are widely used in computer simulation codes such as LS-DYNA [4], CONWEP [5] and AT-Blast [6].

Due to their extensive use in building and infrastructure, offshore, and mining applications, thin-walled metal hollow section members are among key structural element types that are susceptible to large deformations during a blast event. Remennikov and Uy [7] presented experimental results from explosive testing of hollow and concrete filled tubular columns. They also proposed simplified engineering-level models for the near-filed blast impulse to predict the response of structural members. Considerable investigations have been conducted on thin-walled hollow structural members subjected to transverse blast loads. Karagiozova et al. [8] developed a two-phase deformation model of a hollow section beam for revealing its characteristic features, namely deformation and energy absorption under a near-field blast. The proposed model described the temporal variation of local and global deformations, which is considered the most common failure mechanism of thin-walled hollow section members subjected to transverse blast loads. Bambach [9] also highlighted that thin-walled hollow sections often sustain substantial local deformations and/or collapse of the cross-section, in addition to global displacement of the members. Two failure mechanisms were observed by Bambach [9] through the experiments carried out under controlled conditions. Once the high impulsive pressure front meets the faces of the hollow section beam/column, it undergoes a local deformation. At this stage, most of the energy is absorbed by the deformation of the cross-section rather than transferring to a global deformation of the member. Once the section has collapsed/squashed, global deformation dominates the deformation process, whereby only a portion of the total energy that is transferred from the original source is absorbed. However, due to the collapse/squashing of the cross-section, the energy absorption capacity of the section is decreased, which consequently increases the deformation. Therefore, the 
prediction of total deformation based on energy absorption is a complicated task (as also highlighted by Bambach [9]). It is also noted that in near-field detonations, the scaled standoff distance has a considerable influence on the final failure patterns.

Experimental and analytical investigations of hollow and concrete-filled steel square hollow section (SHS) clamped beams subjected to a low velocity, high mass transverse impact at the mid-span have been carried out by Bambach et al. [10]. Comparisons have been made between static and dynamic loading conditions and the effect of concrete filling on the sections. It has been found that due to the reduction in local deformation at the critical sections, the sectional moment capacities have increased by $83 \%$ compared with the unfilled concrete beams. This has resulted in a decreased total deflection of beams in non-compacted concrete-filled tubes. However, the results obtained for compacted concrete-filled tubes have shown that concrete filling precludes the formation of local deformations beneath the impactor. The energy absorption capacity until failure of the beams is reduced by the concrete filling for non-compact sections, due to a reduction in the deflection at failure. The strengthening effect and change in failure deflection becomes negligible for compact sections because of the fact that hollow compact sections do not suffer from local deformations beneath the load point, and concrete-filled compact sections behave similarly to hollow compact sections. In general terms, the transverse force resistance is shown to be significantly larger than the plastic collapse load due to the axial (tension) membrane action associated with axial restraints. This provides a substantial reserve of strength that can be realised under extreme loading conditions from impact or blast environments.

Jama et al. [11] have tried to quantify the energy dissipated during the local and global deformation mechanism of steel hollow sections subjected to transverse explosive loads. It has been highlighted that more than $50 \%$ of the total energy was dissipated during local deformations, whilst the remainder was dissipated due to plastic deformations. In addition, an 
analytical method based on rigid-plastic analysis and yield line analysis has been developed by Jama et al. [11]. As local and global deformations of near-field detonations are considerably involved in non-linear large plastic deformation analysis, it is recommended to have a non-linear analysis in order to obtain accurate results. On the other hand, a similar attempt to propose an analytical model has been made by Karagiozova et al. [8]. The proposed model can describe the temporal variation of local and global deformations when the strain rate effects are taken into account during both phases of deformation. Such model has been validated using the results published by Jama et al. [11, 12].

The objective of the present study is to investigate the deformation mechanism of hollow and concrete-filled SHS columns under close-in detonations using experimental and numerical approaches. Three different configurations were used in these numerical and test programs namely; C1 (Hollow SHS tube at a standoff distance of $100 \mathrm{~mm}$ from the detonator), C2 (Concrete filled SHS tube at a standoff distance of $100 \mathrm{~mm}$ from the detonator), C3 (Concrete filled SHS tube at a standoff distance of $150 \mathrm{~mm}$ from the detonator). A comprehensive numerical modelling technique using the Arbitrary Lagrangian-Eulerian (ALE) method given in the finite element (FE) code LS-DYNA [4] has been used in the analysis. The validated models were subsequently used to predict the force, permanent plastic deformation, deformation history, stress distribution and energy absorption capacity of the different configurations of beams. In addition, the energy absorption capability of concrete-filled and unfilled configurations have also been quantified and discussed.

\subsection{Experimental Setup}

Detailed description of live explosive testing of the steel column specimens subjected to nearfield blast loading is provided by Remennikov and Uy [7]. In the experimental study coldformed SHS with sectional dimensions of 100 x $5 \mathrm{~mm}$ (Grade C350 from OneSteel) were 
used. End concrete blocks of $50 \mathrm{~mm}$ (W) x $350 \mathrm{~mm}$ (D) x $400 \mathrm{~mm}$ (H) were designed to provide additional inertial resistance to the specimens in order to prevent their excessive rebound. These blocks were placed at both ends as the supports for the SHS column. The column specimens had a clear span of 2.0 metres between the end blocks. The geometry and section details of the column specimens are shown in Figure 1. The columns were tested in a horizontal position and were supported by the concrete blocks, with the embedded steel channel sections welded to the ends of the columns. The concrete end blocks were freestanding on the ground and can rotate in response to large deformations of the columns. Hence, the horizontal column specimens were idealised as simple supports under blast loading. The ground clearance was $250 \mathrm{~mm}$.

\section{[Figure 1]}

The explosive load was provided by a cubic charge of trinitrotoluene (TNT) placed at an appropriate stand-off distance above the column surface (Figure 1 (b)). The required standoff distances were created using polystyrene spacers. TNT charges were prepared by casting molten TNT into $120 \mathrm{~mm}$ cubic moulds. A pentolite booster with an integrated detonator was cast into the TNT cube charges to facilitate a central charge detonation from the top. The average density of TNT was $1500 \mathrm{~kg} / \mathrm{m}^{3}$ and the average mass of the explosive charges was $2.6 \mathrm{~kg}$. All explosive charges were detonated using an electric initiation system.

The three different test configurations (C1-C3) with scaled stand-off distances are given in Table 1.

[Table 1]

\subsection{Numerical Model Development}


A comprehensive, non-linear three dimensional numerical analysis using the ALE method in LS-DYNA [4] was conducted to investigate the response of the concrete-filled square tubular columns subjected to blast loading due to close range detonation of the TNT charges. A detailed view of the finite element model is given in Figure 2. The model consists of an air domain, concrete supports, embedded channel sections, the SHS beam and the blast source. The surrounding atmospheric (air) domain and concrete fill were modelled using solid elements whilst the tubular column, concrete supports, channel section were modelled using shell elements. Shell boxes which replicate concrete supports were given added mass to match with the weight of the concrete blocks. Shell boxes were rigidly connected to the channel section and allowed to freely rotate on the ground surface.

High explosives were modelled using an Eulerian mesh, specifically the *INITIAL_VOLUME_FRACTION_GEOMETRY card with the appropriate distances of the different experimental configurations. The *CONTRAINED LAGRANGE _IN _SOLID card was coded to produce the interaction between the air domain and the Lagragian bodies.

[Figure 2]

The configuration C1 (hollow tube) consists of 640,000 solid elements and 28,900 shell elements, and the configurations $\mathrm{C} 2 / \mathrm{C} 3$ (filled with concrete) consist of 677,500 solid elements and 28,900 shell elements. The mesh density of the air domain in the vicinity of the beam was increased to capture local and global deformations of the steel columns accurately. This was important as larger mesh sizes near the edges of the beam may not provide the required coupling effect between the ALE domain and the Lagrangian parts, and may subsequently cause inaccuracies in the numerical results. The mesh size used near the centre of the air domain was $3 \mathrm{~mm}$, which was increased to $5 \mathrm{~mm}$ near the boundaries. In order to capture the failure pattern of the beam at the mid-span, the mesh size of the steel beam was 
set to $3 \mathrm{~mm}$. Several preliminary analyses were performed prior to the selection of appropriate mesh sizes for each domain.

\subsection{Steel Material Parameters}

The behaviour of the mild steel tube was modelled using the material card *MAT_PIECEWISE_LINEAR_PLASTICITY by incorporating the Cowper Symonds strain rate parameters and the user-defined base curve for stress-strain, as given in Table 2 and Figure 3. This material has been effectively utilised by different researchers in previous studies to predict the material behaviour of mild steel under large deformations [13-15].

[Figure 3]

[Table 3]

\subsection{Concrete Material Parameters}

There are several material models available in LS-DYNA [4] that are capable of predicting the high strain rate behaviour of concrete. *MAT_CONCRETE_DAMAGE (MAT_72R3 and MAT_72), *MAT_WINFRITH_CONCRETE (MAT_84/85), *MAT_PSEUDO_TENSOR (MAT_016), *MAT_CSCM_CONCRETE (MAT_159), *MAT_JOHNSON HOLMQUIST CONCRETE (MAT_111), *MAT_SOIL AND FOAM (MAT_005), are among many other models available in LS-DYNA. Among these material models, *MAT_72R3 is considered as one of the most accurate models to predict the high strain rate deformation of concrete. This model has also been identified as one of the most efficient material models available in LSDYNA that predicts the behaviour of concrete because it only needs two input material constants. Based on the material's compressive strength and density, LS-DYNA calculates the other relevant material parameters prior to the analysis. Grade 35 concrete has been used 
in this experimental study to fill the steel tube and to build the supporting concrete blocks (the material parameters are given in Table 2). *MAT_ADD_ERROSION card was used to incorporate the concrete failure by defining the maximum principle strain as $1 \%$.

[Table 4]

\subsection{Properties of Air and Explosive Material}

The ambient air was modelled with the *MAT_NULL card by combining the polynomial Equation of State (EOS) (Eq. (1)). In the material card, the pressure cut-off option was included to limit the pressure that can be generated by the tensile loading. This parameter was kept at zero since air does not resist tension. All parameters assumed for air under the material card *Mat_Null have been tabulated in Table 3.

$$
P=(\gamma-1) \frac{\rho}{\rho_{0}} E
$$

The explosives were modelled using the *MAT_HIGH_EXPLOSIVE_BURN card with the Jones-Wilkins-Lee (JWL) EOS (Eq. (2)). The parameters adopted in the simulation are tabulated in Table 3.

$$
P=A\left(1-\frac{w}{R_{1} V}\right) e^{-R_{1} v}+B\left(1-\frac{w}{R_{2} V}\right) e^{-R_{2} v}+\frac{w}{V} E
$$

[Table 5]

where $\mathrm{P}$ is the pressure. Selection of the correct detonation velocity and Chapman-Jouget pressure in numerical simulations is important in order to replicate the detonation in the experiments. Mesh refinement was performed close to the blast source to ensure the correct transfer of initial pressure to the surrounding environment. The detonation was initialised via 
the *INITIAL_DET card, with the initial detonation point set at the top-center of the cubic charge.

As the simulation of the ALE model is computationally expensive, the boundaries of the surrounding air domain cannot be extended too far beyond the outer lines of the subject's geometries. This can cause a reflection of pressure waves at the boundaries of the air domain. To overcome this issue, the *BOUNDARY_NON_REFLECTING card was applied for all surfaces of the air domain, except the bottom surface and the planes of symmetry. As in the real blast scenario, and especially the configurations considered in this study, considerable pressure reflections are generated from the ground. Therefore, in order account for such reflections, the bottom side of the air domain does not incorporate non-reflective segments. The outside pressure from this constrained domain was set to atmospheric pressure through the *CONTROL_ALE card.

The interaction between the air (fluid) and the Lagragian parts (Solids) was simulated using the *CONSTRAINED_LAGRANGE_IN_SOLID algorithm. This allows for the interaction between the air and Lagragian elements with different materials, thereby sharing the same space in the model and interacting with each other. Steel channel sections were used to connect the steel tubular column and the concrete blocks. The outer casing of the concrete blocks were modelled with shell elements and placed on a rigid plane, which allow it to rotate in the plane of bending of the column, similar to the experimental investigation. Additional masses were added symmetrically to the shell boxes to match the masses of the concrete supports. Steel channel sections connected to the beam were embedded in the shell concrete box. The interaction between two parts were provided using the *CONSTRAINED_NODAL_RIGID_BODY algorithm. This assumption of rigid interaction between concrete blocks and embedded channel sections does not affect the results as no separations of those two parts were observed during the experiments. The penalty coupling 
option was selected for coupling all parts with the air domain. As the ALE method is computationally expensive, it is important to keep the time-step within $10^{-6}-10^{-7}$ (s) to achieve accurate results within a reasonable time period. On the other hand, the total simulation time required for observing the complete deformation process is approximately $20 \mathrm{~ms}$. Therefore, the time-step of the analysis was kept closer to $5 \times 10^{-7} \mathrm{~ms}$. Gravitational acceleration was applied to all parts using the *LOAD_BODY card.

\subsection{Results and Discussion}

\subsection{Configuration C1 - hollow tube, scaled stand-off distance of $0.12 \mathrm{~m} / \mathrm{kg}^{1 / 3}$}

Specimen C1 was subjected to an explosion resulting from a cubic TNT charge that was positioned $100 \mathrm{~mm}$ above the column's top surface using the polystyrene spacer. The charge was detonated from the top using an electronic detonation system. Comparisons of the numerical results with the experimental observations are presented in Figure 4 (a) and (b).

[Figure 4]

Numerical simulations were able to predict the failure mode reasonably well, as shown in Figure 4 (a) and (b). It can be observed from Figure 4 that the column experienced a large global flexural deformation and a localised breaching failure of the tube's top and bottom flanges. This explosion can be classified as the 'near-field' gas-dynamic regime characterised by the fireball engulfing the column and impinging high pressure detonation gases. The time history of the pressure and impulse development near the centre of the beam confirms this argument. Once the detonation product gases impinge the top flange of the beam, it deforms downwards and contacts the bottom flange. This high speed impact loading causes the bottom flange to fail. A comprehensive analysis of the mid-span section deformation-time histories is 
presented in Section 4.3. Simultaneously, sideway bulging of the vertical flanges occurs due to very high outwards pressure inside the section. Curling of the free ends of the top flanges towards the crater was observed in both numerical and experimental programs. During the global deformation process, the beam moved towards the ground until it impacted the ground surface. From the experimental and computational observations, it can be concluded that the hollow SHS tube is likely to experience a breaching failure of the cross-section and a severe global deformation when subjected to a close-range blast with a scaled standoff distance as close as $0.12 \mathrm{~m} / \mathrm{kg}^{1 / 3}$.

\section{[Figure 5] [Figure 6] [Figure 7]}

Figure 5 shows the pressure-time history of the reflected overpressure measured at four different locations on the top surface of the beam. The incident pressure at the point just above the top surface of the beam (at $95 \mathrm{~mm}$ from the centre of detonation) is approximately about $200 \mathrm{MPa}$ for the $\mathrm{C} 1$ configuration while reflected overpressure has increased to approximately $650 \mathrm{MPa}$. The impulse produced at the same location was obtained by integrating the pressure-time history as presented in Figure 6. The impulse generated in this particular configuration is estimated at approximately $17 \mathrm{MPa}-\mathrm{ms}$. An accurate estimation of the peak pressure and the impulsive load is important in the design of such members to survive under these severe load conditions. Figure 7 shows the blast pressure development history for the configuration $\mathrm{C} 1$ and the non-spherical shape of expansion of the detonation product gases for the cubical charge.

\subsection{Configuration C2 - concrete-filled tube, scaled stand-off distance of $0.12 \mathrm{~m} / \mathrm{kg}^{1 / 3}$}

In order to directly compare the failure modes of the hollow and concrete-filled square sections, specimen $\mathrm{C} 2$ included concrete infill and was tested at the same stand-off distance as specimen $\mathrm{C} 1$ (the hollow tube section). The cubic TNT charge was placed $100 \mathrm{~mm}$ above 
the top face of the column using the polystyrene spacer and was detonated from the top. The failure modes of specimen $\mathrm{C} 2$ obtained from the experiments are presented in Figure 8.

[Figure 8]

It was observed for specimen C2 (where concrete infill was used), the local plastic deformation at the mid-span section was severe, but breaching failure was prevented by the concrete infill. When the products of detonation impinge on the top flange of the beam, it transfers the load to the concrete infill and to the bottom flange. During the next stage of the deformation, the concrete crushes in the vicinity of the centre of the beam and it starts to undergo local deformation. The experimental results show an unsymmetrical deformation in the failure pattern (Figure 8). This can be attributed to the presence of a minor eccentricity of the blast source or irregularities in the cross-section of the SHS. However, the simulations were able to predict the deformation pattern and the absence of a column breach at the midspan section quite well.

The experiential and numerical results presented in Figure 4 and 8 provide an opportunity for both qualitative and quantitative analyses of the response of steel square tubes with and without concrete infill that are subjected to the near-field regime of explosive loading. It can be seen that both types of columns experienced a combination of global flexural response and severe localised plastic deformation of the central zone. The concrete-filled section was not breached by the blast, unlike the hollow section subjected to the same explosive loading. The maximum displacement of the column can be greater than $250 \mathrm{~mm}$, since the column's rotation was terminated by the ground surface.

The time histories of the pressure and impulse acting on the top surface of the SHS beam are given in Figure 9 and Figure 10. It has also been compared with the impulse-time history given for configuration $\mathrm{C} 1$ (where the same blast source was placed at a scaled stand-off 
distance of $0.12 \mathrm{~m} / \mathrm{kg}^{1 / 3}$ ). A minor increase in the reflected overpressure and the impulse was observed through the numerical results. For the configuration $\mathrm{C} 1$, the impulse acting on the SHS tubular beam was measured as $17.8 \mathrm{MPa}-\mathrm{ms}$, whilst the concrete filled configuration produced an impulse of 19 MPa-ms. Similarly, the reflected overpressure for the configuration $\mathrm{C} 1$ is estimated as $680 \mathrm{MPa}$ whilst $\mathrm{C} 2$ produced an overpressure of $700 \mathrm{MPa}$. This shows that the structural stiffness contributes towards the peak values of reflected pressure and impulse.

[Figure 9] [Figure 10]

With the failure at the mid-span section of the beam subjected to a severe impulsive load, the beam loses its stiffness. The main advantage of the concrete as a filling material is its ability to absorb part of the initial energy that is imparted to the steel beam. If the beam can withstand this initial high intensity and very short duration pressure, it will survive without incurring major damages to the section.

\subsection{Configuration C3 - concrete-filled tube, scaled stand-off distance of $0.15 \mathrm{~m} / \mathrm{kg}^{1 / 3}$}

The scaled stand-off distance was further increased to $0.15 \mathrm{~m} / \mathrm{kg}^{1 / 3}$ for specimen $\mathrm{C} 3$ as in [7] in order to investigate the response of the concrete-filled steel square tube. The blast environment at this stand-off distance is still categorised as a 'near-field' regime, with the explosive loading generated predominantly due to the engulfment of the column by the products of detonation. The cubic TNT charge was placed at $150 \mathrm{~mm}$ above the top surface of the specimen using the polystyrene spacers. The charge was initiated from the top using an electronic detonator. The failure mode of specimen C3 is presented in Figure 11.

[Figure 11] 
In this configuration, no failure was observed in the beam experimentally [7] and in the numerical simulations. The column cross-section near the centre was severely squashed, but the concrete infill seems to have provided an internal support to the tube walls and prevented steel rupture, breaching failure, and local buckling failure of the tube walls at the mid-span. The bulging effect at the cross-section measured from the experiments matched reasonably well with the numerical simulations. The measured width of the bulged mid-section of the column was $158 \mathrm{~mm}$, and the numerical simulation prediction was $169 \mathrm{~mm}$. The accuracy of the results for configurations $\mathrm{C} 2$ and $\mathrm{C} 3$ significantly depend on the failure strain definition of the concrete and steel materials. The time history of the deformation for configuration C3 is given in Figure 12. Due to high demanding computational resources (12 hrs with 16 GB RAM with 8 processors) involved in the simulations, once the centre of the beam reaches its peak, the simulation was stopped. The maximum deformation predicted by the numerical simulations was $155 \mathrm{~mm}$, which was in good agreement with the experimental prediction of $152 \mathrm{~mm}$. Figure 12 also shows the comparison of the ALE-based numerical simulation with the simplified engineering level models of predicting the total blast impulse for near-field blast loading proposed by Remennikov and Uy in [7]. The high-fidelity physics-based simulation results obtained in this study compare very favourably with the damage predictions by the simplified techniques in [7].

[Figure 12] [Figure 13] [Figure 14]

Figure 13 and 14 show the time histories of the reflected pressure and the specific impulse at four different locations along the beam. Distances were measured from the center line of the TNT charge with an increment of $0.2 \mathrm{~m}$. The reflected overpressure at $0.8 \mathrm{~m}$ distance was approximately $26.5 \mathrm{MPa}$ whilst the $0.8 \mathrm{~m}$ gauge measurement read as $6 \mathrm{MPa}$. It was also observed that the impulse drops by a considerable percentage with the measured distance from $0.2 \mathrm{~m}$ to $0.8 \mathrm{~m}$. 
The von Mises stress developed in the SHS during the initial phase of deformation, which was obtained from the numerical simulation for configuration $\mathrm{C} 3$ is presented in Figure 15. This shows high stress development in the vicinity of the mid-section of the tubular column that undergoes local deformations. It also highlights the capabilities of the *MAT_PIECEWISE_LINEAR_PLASTICITY material model to capture high strain rate behaviour of such materials accurately, as the stress obtained from the numerical simulations agree with the quasi-static stress-strain prediction. This also highlights the importance of employing such material models in the analysis of large deformation problems so as to capture the deformation fairly accurately.

[Figure 15]

Comparison of the blast response and failure modes for specimens $\mathrm{C} 2$ and $\mathrm{C} 3$ in Figure 8 and 11 demonstrates a remarkable improvement in the performance of the concrete-filled tube following the increase in the scaled stand-off distance from $0.012 \mathrm{~m} / \mathrm{kg}^{1 / 3}$ to $0.15 \mathrm{~m} / \mathrm{kg}^{1 / 3}$. The maximum residual displacement for C3 was about $152 \mathrm{~mm}$, which is significantly less than that for specimen $\mathrm{C} 2$.

It can be deduced from the above discussion that the key energy absorption mechanism of the SHS tubular columns is related to severe localised deformation of the projected charge section. Therefore, the following section analyses the local deformation phase of the midspan section of the column in detail.

\subsection{Local Deformation and Energy Absorption}

Bambach et al. [9] identified several local deformation patterns of hollow tubular sections under transverse uniformly distributed blast loads. Also highlighted was the importance of 
relating the hinge formation and local deformation patterns with the support conditions. Similar behaviour with two phases of deformation of the tubular column was identified in this study. The initial phase is dominated by local deformation, while the second phase is dominated by global deformation. Plots of the local deformation process for configurations $\mathrm{C} 1$ and $\mathrm{C} 3$ are shown in Figure 16 and 17. The major difference between the two configurations is the fracture mechanism of the steel beam in the vicinity of the mid-span of the beam. Time histories show that this local deformation for the given configurations occurs in the range of $0-0.65 \mathrm{~ms}$. During this short period of time, the tubular section undergoes considerable plastic deformation, thereby absorbing significant amount of energy. The next section discusses this in more detail.

[Figure 16-17]

Local deformation starts immediately after the impulse impinges the top flange. Crack formation starts at the edges of the top flange and propagates outwards. It is also observed that after this time period, the global deformation is dominated by a considerable transverse displacement. Therefore, two phases of deformation have been clearly identified: local deformation dominating the initial time period (short), whilst the transverse deflection dominates a major portion of the deformation history. Figure 18 shows the local transverse deformation history of the mid-span section of the column for configuration C3. Local deformation occurred during a considerably short period of time of approximately $0.65 \mathrm{~ms}$ compared to the global deformation time period of $12.5 \mathrm{~ms}$. Therefore, for clarity, the time history of the deformation of the mid-node of the top flange has been extracted from the complete deformation time history, and is presented in Figure 18. In configuration C3, the local deformation observed was $110 \mathrm{~mm}$, while $\mathrm{C} 1$ shows a local deformation of $40 \mathrm{~mm}$ before it fractured and failed. 
[Figure 18-19]

The concrete infill assisted in absorbing the initial blast energy, and therefore helped to reduce the initial local deformation of the critical section (mid-span) of the tubular column. Once the beam survived the initial impulsive loading through local deformation, there was no major deformation observed in the critical section of the beam (Figure 19). Therefore, the significant amount of energy that was imparted to the composite beam has been dissipated through the crushing of concrete fill. This has also a number of cracked segments produced of the concrete at different locations along the beam. Therefore, it is worthwhile to examine the energy distribution between these two distinct phases in order to evaluate the performance of such members under transverse blast loads.

[Figure 20]

Figure 20(b) shows the extracted time history of Figure 20(a), the internal energy absorption of the beam with concrete infill. It is interesting to note that $70 \%$ of the total internal energy is absorbed by the beam during the initial local deformation stage. The beam has absorbed 50-60 kJ within the initial local deformation phase (approx. $0-0.7 \mathrm{~ms}$ ), whilst the total energy absorption capacity reached a stable $65 \mathrm{~kJ}$ at around 3-4 ms. This highlights the importance of filling materials such as concrete infill in structural elements to reduce the damage to structures. Once this stable value of local energy absorption is reached through deformation, the balance energy will be transferred to the beam and then converted into kinetic energy.

\subsection{Conclusions}

This study evaluates the performance of concrete-filled tubular SHS columns subjected to a near-field blast. The experimental findings were validated through a comprehensive 
numerical modelling program. The failure patterns, deformation histories, and energy absorption of the hollow and concrete-filled SHS tubular columns were investigated and presented.

Two distinct phases of deformation were identified. The initial stage of deformation was dominated by the local deformation of the tubular column, whilst the second phase of the deformation was dominated by the transverse flexural global deformation. The results predicted by the numerical simulations were in close agreement with the experimental results.

It has been shown that the local deformation of the tubular column plays a key role in energy absorption, and a significant portion of the energy imparted to the column was absorbed through the local deformation mechanism. During this process, the critical mid-span was subjected to significant plastic deformations. During the next phase of deformation, the transverse deflection of the column dominated.

The concrete-filled column exhibited less transverse deformation compared to the hollow tubular section. Concrete crushing is the energy absorbing mechanism of the concrete-filled SHS tubes.

The Arbitrary Lagrangian-Eulerian (ALE) based numerical simulation method adopted in this study demonstrated significant capabilities in predicting the failure mechanism of tubular columns subjected to near-field blast loading.

Therefore, the experimental and numerical techniques developed through this study can be used in future applications of SHS columns in structures that are prone to deform under nearfield blast loads.

\section{Acknowledgements}


The authors would like to thank the technical staff at the laboratories of the University of Wollongong and the University of Western Sydney for assisting with manufacturing the specimens and conducting the tests.

\section{References}

[1] Svantesson, P., Simulations of the Response of Concrete Structures Subjected to Air Blasts, Master's Thesis, Lund University, Sweden., 2013.

[2] Kingery, C.N. and B. G, Airblast Parameters from Tnt Spherical Air Burst and Hemispherical Surface Burst. US Army Armament Research and Developemnt Centre, BRL, Aberdeen Proving Grounds, Maryland (April, 1984).

[3] UFC-3-340-02 Structures to Resist the Effect of Accidential Explosions,, Department of Defence, 2008, Washinton D.C.

[4] Hallquist, J.O., Ls-Dyna Keyword User's Manual, 2006, Livermore Software Technology Corporation (LSTC), Livermore, California, USA,

[5] CONWEP, User's Guide for Microcomputer Programs Conwep and Funpro - Application of TM 5-855-1, 1988, US Army Engineer Waterways Engineering Station, Vicksburg

[6] AT-Blast, Anti-Terrorism Blast, 2008, Applied Research Associates, Inc.,

[7] Remennikov, A.M. and B. Uy, Explosive Testing and Modelling of Square Tubular Steel Columns for near-Field Detonations. Journal of Constructional Steel Research, 2014. 101(2014): p. 290-303.

[8] Karagiozova, D., T. Yu, and G. Lu, Transverse Blast Loading of Hollow Beams with Square Cross-Sections. Thin-Walled Structures, 2013. 62: p. 169-178.

[9] Bambach, M., Design of Metal Hollow Section Tubular Columns Subjected to Transverse Blast Loads. Thin-Walled Structures, 2013. 68: p. 92-105.

[10] Bambach, M., H. Jama, X. Zhao, and R. Grzebieta, Hollow and Concrete Filled Steel Hollow Sections under Transverse Impact Loads. Engineering Structures, 2008. 30(10): p. 2859-2870.

[11] Jama, H., G. Nurick, M. Bambach, R. Grzebieta, and X. Zhao, Steel Square Hollow Sections Subjected to Transverse Blast Loads. Thin-Walled Structures, 2012. 53: p. 109-122.

[12] Jama, H., M. Bambach, G. Nurick, R. Grzebieta, and X.-L. Zhao, Numerical Modelling of Square Tubular Steel Beams Subjected to Transverse Blast Loads. Thin-Walled Structures, 2009. 47(12): p. 1523-1534.

[13] Mamalis, A., D. Manolakos, M. Ioannidis, K. Spentzas, and S. Koutroubakis, Static Axial Collapse of Foam-Filled Steel Thin-Walled Rectangular Tubes: Experimental and Numerical Simulation. International Journal of Crashworthiness, 2008. 13(2): p. 117-126.

[14] Liu, B., R. Villavicencio, and C. Guedes Soares, On the Failure Criterion of Aluminum and Steel Plates Subjected to Low-Velocity Impact by a Spherical Indenter. International Journal of Mechanical Sciences, 2014. 80: p. 1-15.

[15] Liu, B., R. Villavicencio, and C. Guedes Soares, Experimental and Numerical Plastic Response and Failure of Pre-Notched Transversely Impacted Beams. International Journal of Mechanical Sciences, 2013. 77: p. 314-332. 


\section{List of Tables}

Table1. Configuration details

Table 2. Material parameters for steel and concrete

Table 3. Material and equation of state (EOS) parameters for air and explosives 
Table 1. Configuration details

\begin{tabular}{lllcc}
\hline Test \# & Column & Specimen design & Stand-off & Explosive \\
& specimen & & distance, $\mathrm{m}^{\prime} \mathrm{kg}^{1 / 3}$ & charge \\
\hline 1 & C1 & 100x5 SHS, hollow & $100 \mathrm{~mm}$ & $2.603 \mathrm{~kg} \mathrm{TNT}$ \\
\hline 2 & C2 & 100x5 SHS, concrete infill & $100 \mathrm{~mm}$ & $2.605 \mathrm{~kg} \mathrm{TNT}$ \\
\hline 3 & C3 & 100x5 SHS, concrete infill & $150 \mathrm{~mm}$ & $2.610 \mathrm{~kg} \mathrm{TNT}$ \\
& & &
\end{tabular}


Table 2. Material parameters for steel and concrete

\begin{tabular}{ll}
\hline Parameter & Value
\end{tabular}

\begin{tabular}{ll}
\hline Steel - MAT_PIECEWISE_LINEAR_PLASTICITY \\
\hline Density & $7850 \mathrm{~kg} / \mathrm{m}^{3}$ \\
\hline Elastic modulus & $207 \mathrm{GPa}$ \\
\hline Poison ratio & 0.3 \\
\hline Yield stress & $400 \mathrm{MPa}$ \\
\hline C & 40 \\
\hline P & 5 \\
\hline Failure strain & 0.225 \\
\hline Concrete - MAT_72R3 & \\
\hline Density & $2400 \mathrm{~kg} / \mathrm{m}^{3}$ \\
\hline Compressive strength & $35 \mathrm{MPa}$ \\
\hline Tensile strength & \\
\hline
\end{tabular}


Table 3. Material and equation of state (EOS) parameters for air and explosives

Air TNT

\begin{tabular}{|c|c|c|c|}
\hline Density, $R_{0}$ & $1.293 \mathrm{~kg} / \mathrm{m}^{3}$ & Density, $R_{0}$ & $1500 \mathrm{~kg} / \mathrm{m}^{3}$ \\
\hline Pressure cut-off, & 0 & Chapman-Jouget & $21 \mathrm{GPa}$ \\
\hline $\mathrm{Pc}$ & & pressure, $\mathrm{P}_{\mathrm{cj}}$ & \\
\hline Dynamic viscosity & 0 & Detonation & $6930 \mathrm{~m} / \mathrm{s}$ \\
\hline coefficient & & velocity, D & \\
\hline $\mathrm{C}_{0}-\mathrm{C}_{3}$ & 0 & A & $3.712 \times 10^{11}$ \\
\hline $\mathrm{C}_{4}$ & 0.40 & B & $3.231 \times 10^{9}$ \\
\hline $\mathrm{C}_{5}$ & 0.45 & $\mathrm{R}_{1}$ & 4.15 \\
\hline $\mathrm{C}_{6}$ & 0 & $\mathrm{R}_{2}$ & 0.95 \\
\hline $\mathrm{E}_{0}$ & $2.50 \times 10^{5}$ & $\Omega$ & 0.30 \\
\hline \multirow[t]{2}{*}{$\mathrm{V}_{0}$} & 1.0 & $\mathrm{E}_{0}$ & $7 \times 10^{9}$ \\
\hline & & $\mathrm{V}_{0}$ & 1.0 \\
\hline
\end{tabular}




\section{List of Figures}

Figure 1. (a) Experimental setup for explosive testing of steel square column specimens, (b) TNT at appropriate stand-off distance above column surface

Figure 2. Numerical model detail: (a) Isometric view, (b) Support arrangement, (c) Beam with finite element mesh

Figure 3. Stress-strain behaviour for mild steel at quasi-static strain rate

Figure 4. Local deformation of concrete-filled SHS at mid-section (C1): (a) Experimental results, (b) Numerical prediction (LS-DYNA)

Figure 5. Pressure-time history at $220 \mathrm{~mm}$ from the detonation point for configuration $\mathrm{C} 1$

Figure 6. Impulse-time history at $220 \mathrm{~mm}$ from the detonation point for configuration $\mathrm{C} 1$

Figure 7. Pressure development during the initial phase of the blast for configuration $\mathrm{C} 1$

Figure 8. Local deformation history of concrete-filled SHS at mid-section (C2):

(a) Experimental results (b) Numerical simulation results (LS-DYNA)

Figure 9. Pressure-time history at $220 \mathrm{~mm}$ from the detonation point for configuration $\mathrm{C} 2$

Figure 10. Impulse-time history at $220 \mathrm{~mm}$ from the detonation point for configuration $\mathrm{C} 2$

Figure 11. Comparison of deformation pattern for configuration C3: (a) Isometric view showing the global deformation, (b) Close-up view showing the local deformation

Figure 12. Deformation time history for configuration C3

Figure 13. Pressure-time history along the top surface of the beam: distance measured from the symmetry line (Configuration C3)

Figure 14. Impulse-time history along the top surface of the beam: distance measured from the symmetry line (Configuration C3)

Figure 15. Von Mises stress contours captured during the local deformation phase for configuration C3

Figure 16. Local deformation of SHS tubular column at mid-section (C1)

Figure 17. Local deformation of concrete-filled SHS at mid-section (C3)

Figure 18. Local deformation history of concrete-filled SHS at mid-span of the beam (C3) partial extraction from Figure 32

Figure 19. Concrete crack formation and plastic strain contours

Figure 20. (a) Internal energy absorption history of configuration C1 (b) extracted portion of the energy absorption during localised deformation 

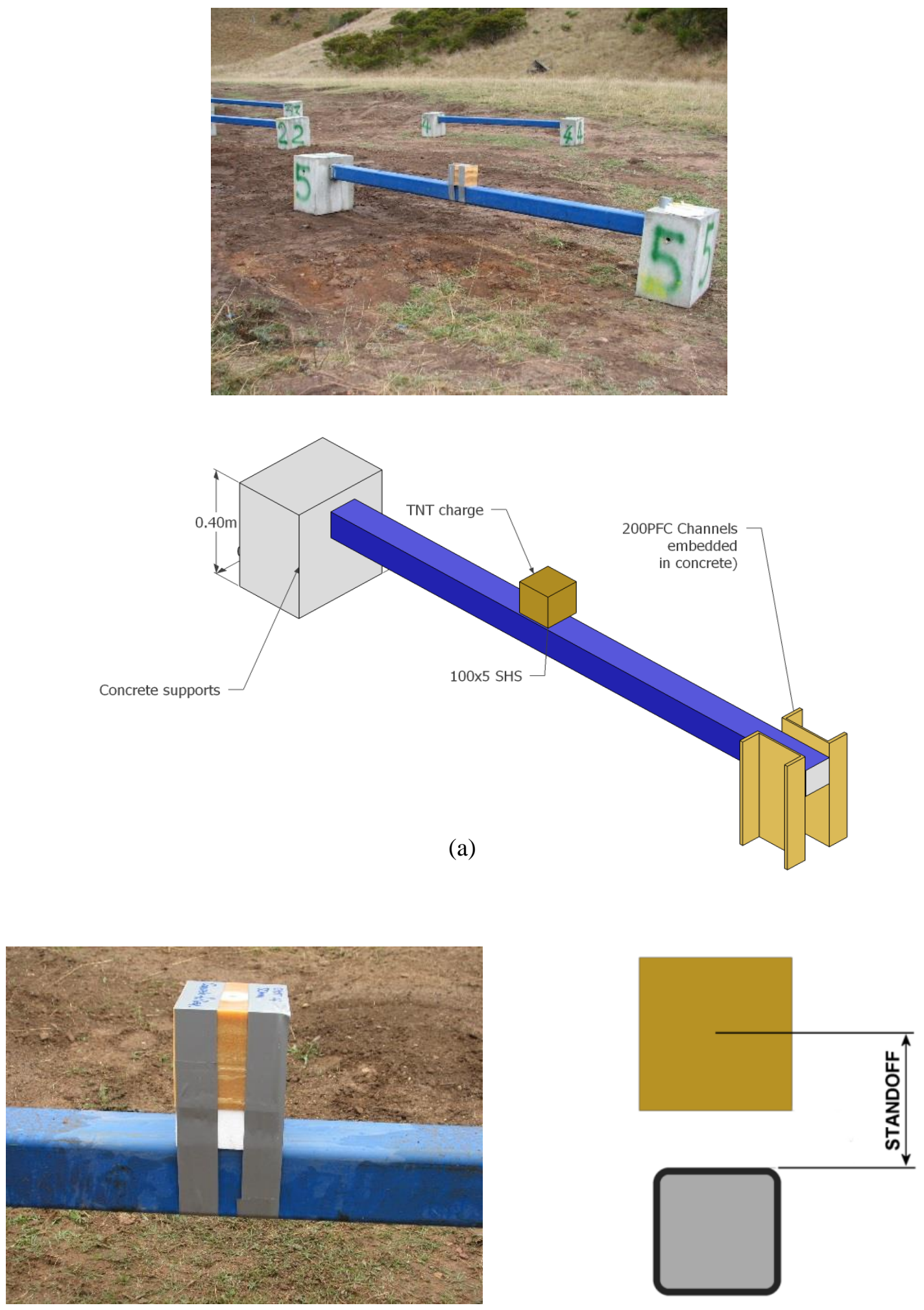

(b)

Figure 1. (a) Experimental setup for explosive testing of steel square column specimens, (b) TNT at appropriate stand-off distance above column surface 


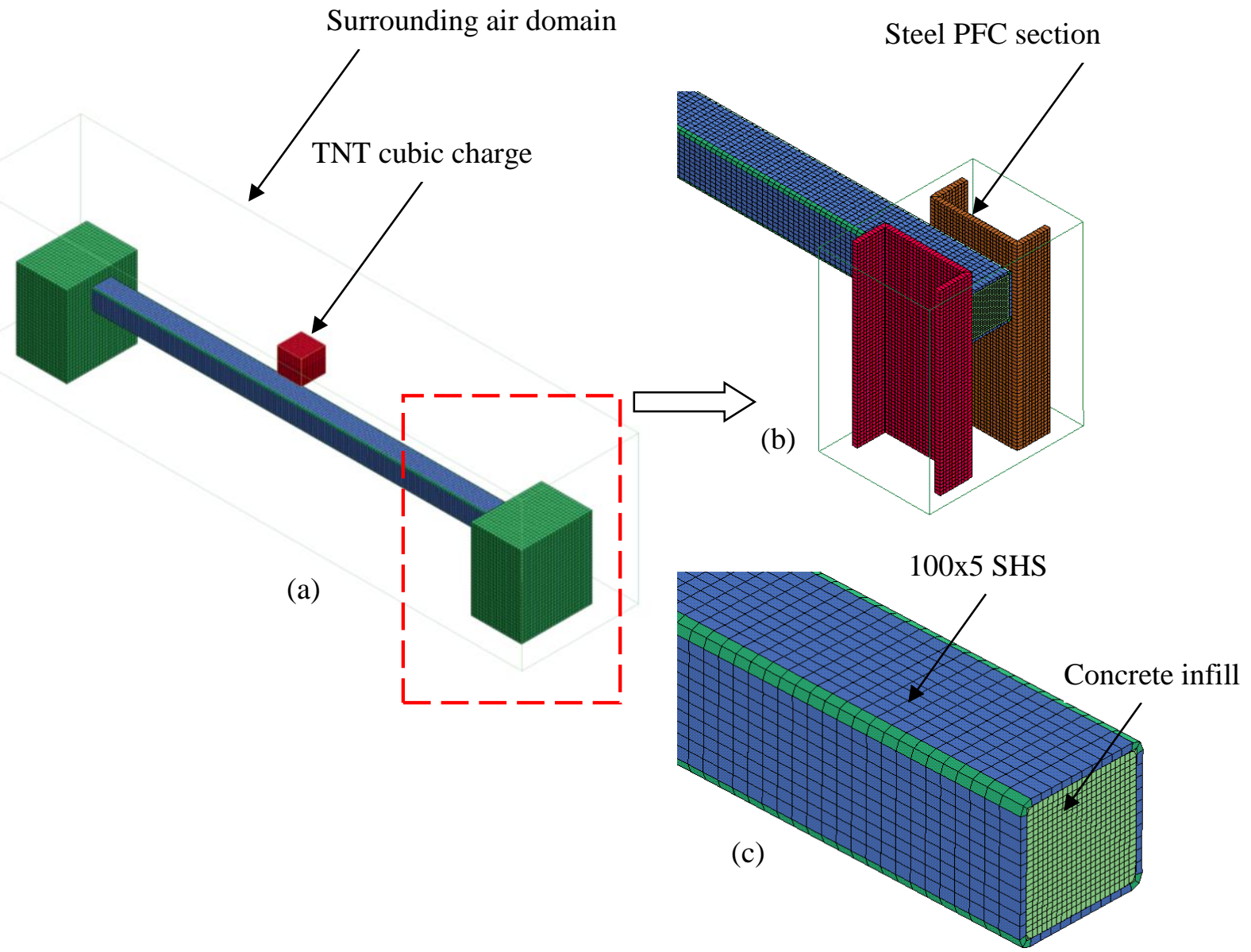

Figure 2. Numerical model detail: (a) Isometric view, (b) Support arrangement, (c) Beam with finite element mesh 


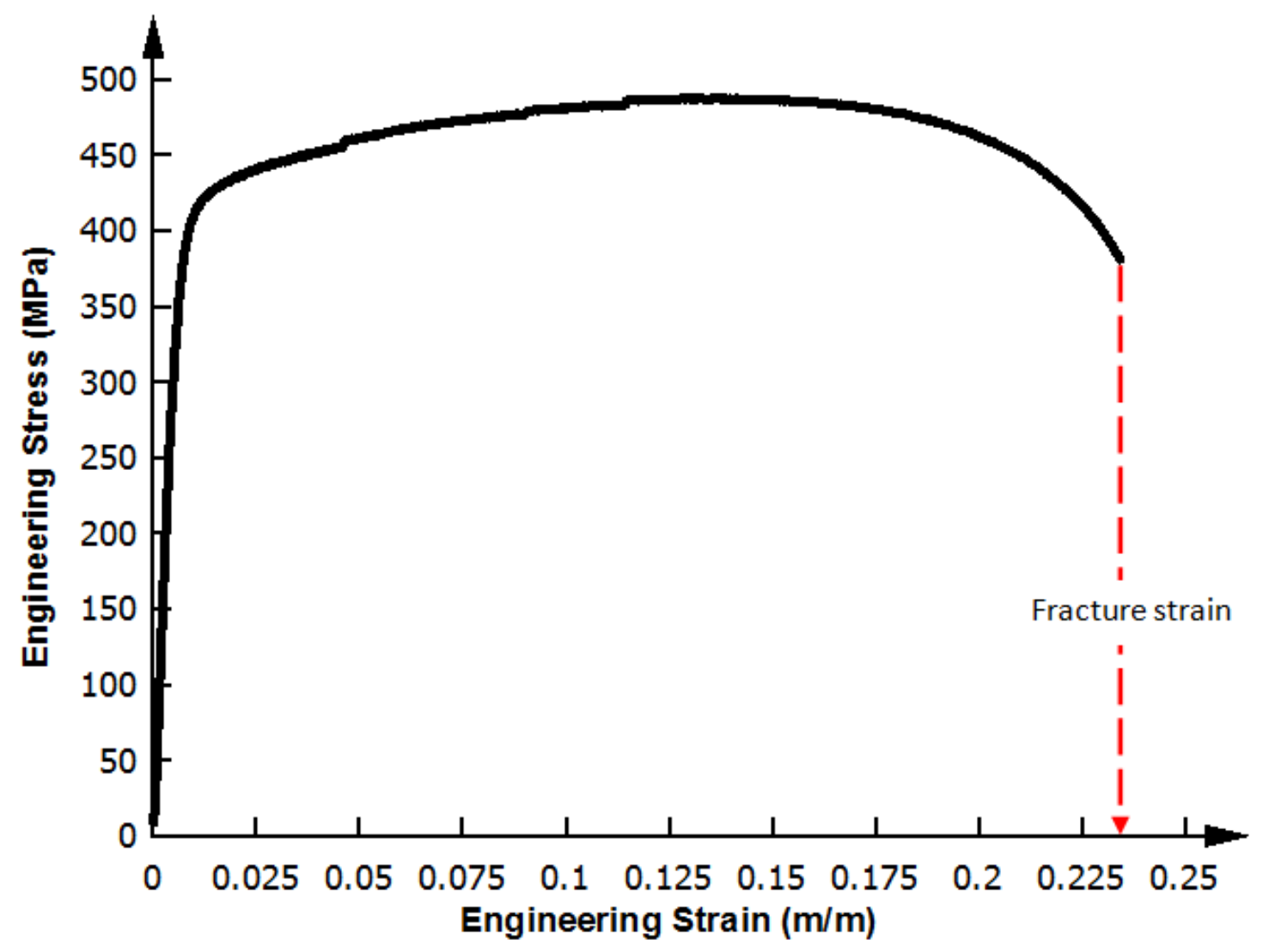

Figure 3. Stress-strain behaviour for mild steel at quasi-static strain rate 


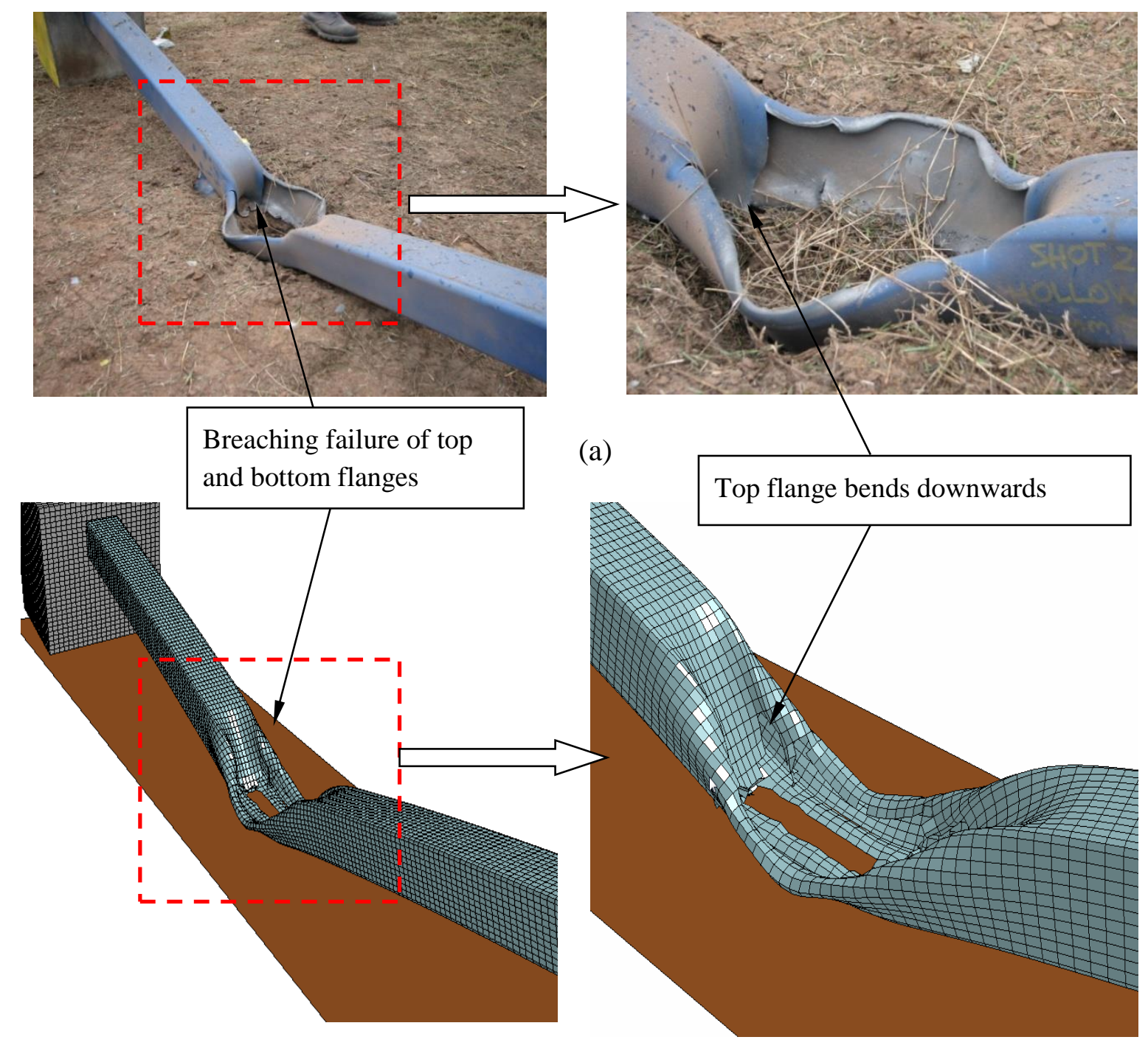

(b)

Figure 4. Local deformation of concrete-filled SHS at mid-section (C1): (a) Experimental results, (b) Numerical prediction (LS-DYNA) 


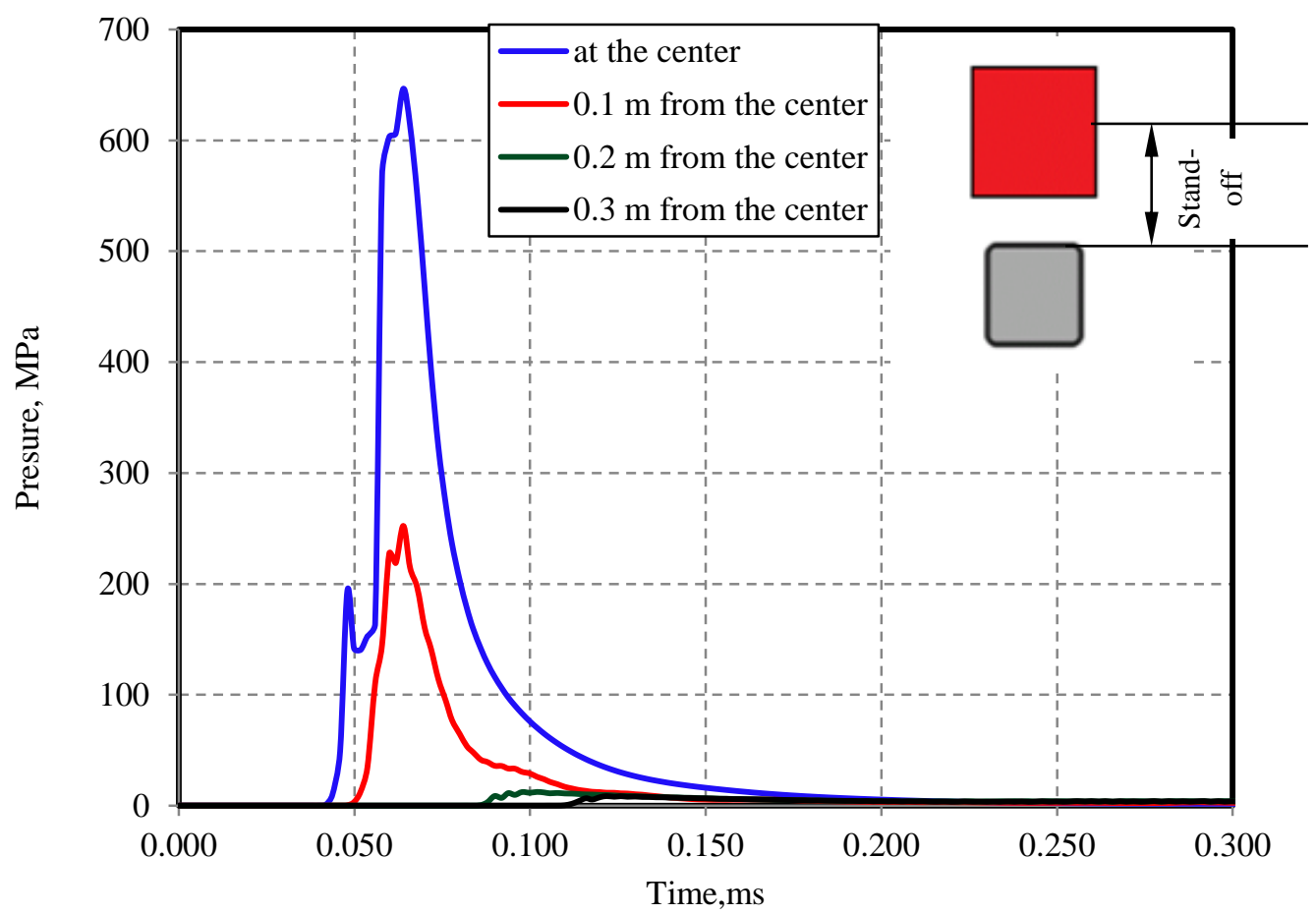

Figure 5. Pressure-time history at the top surface of steel column for configuration C1

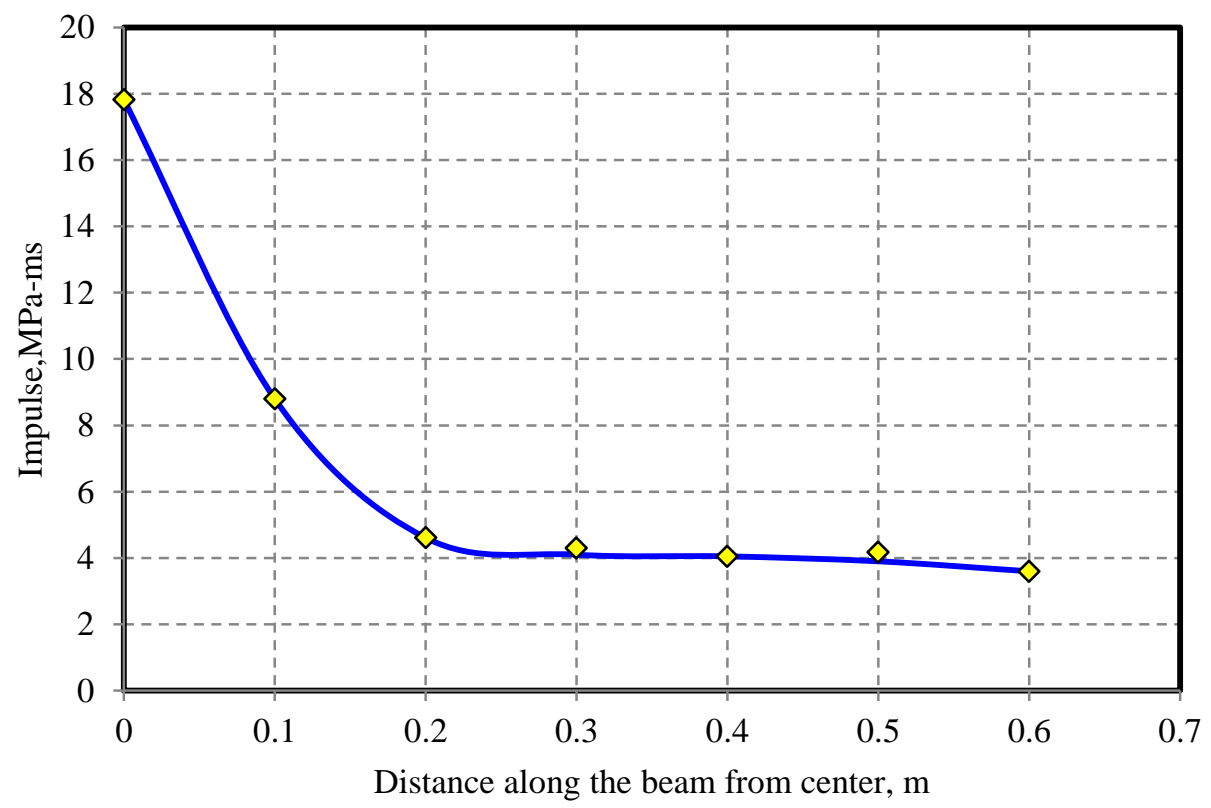

Figure 6. Distribution of maximum impulse along the beam for configuration $\mathrm{C} 1$ 

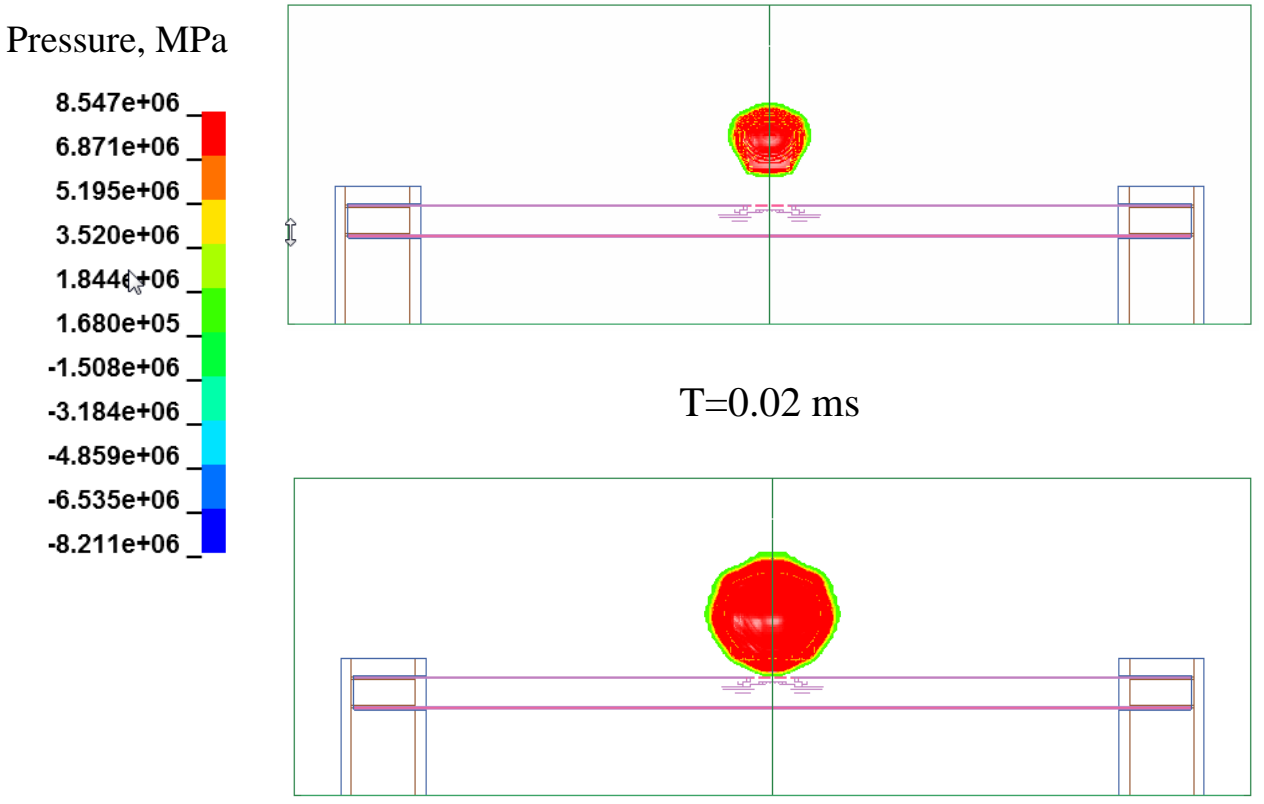

$\mathrm{T}=0.04 \mathrm{~ms}$

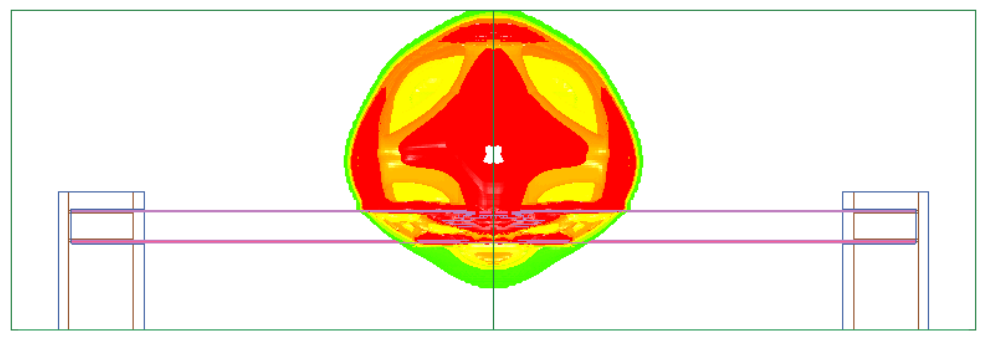

$\mathrm{T}=0.10 \mathrm{~ms}$

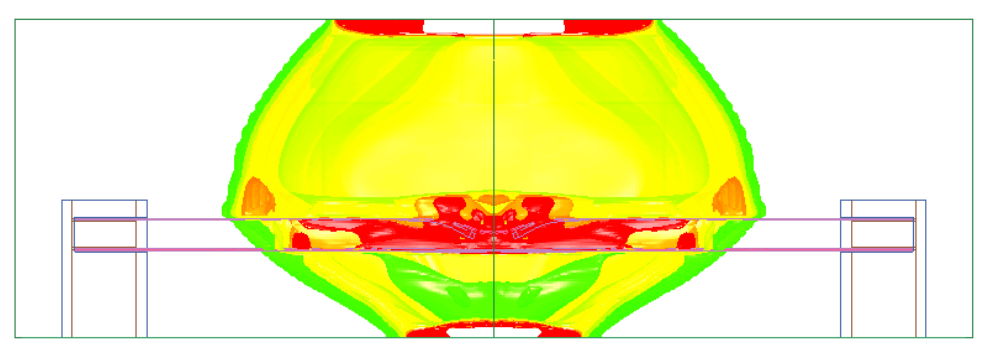

$\mathrm{T}=0.20 \mathrm{~ms}$

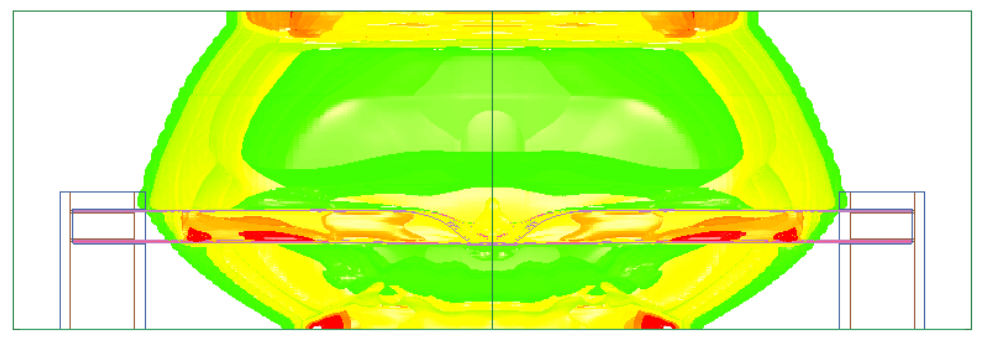

$\mathrm{T}=0.30 \mathrm{~ms}$ 


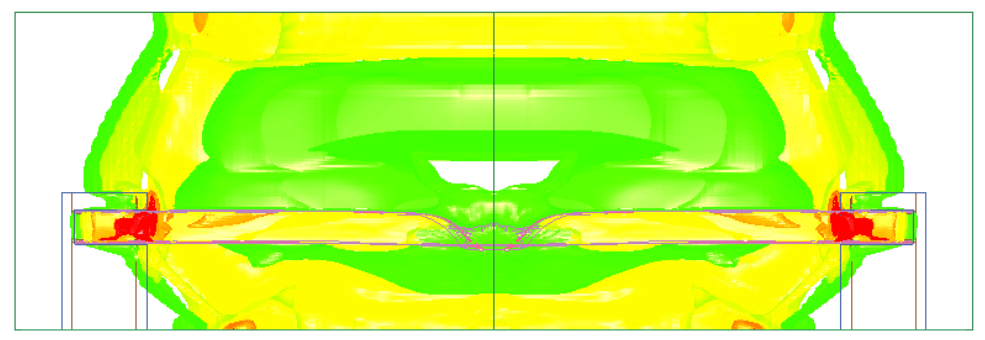

$\mathrm{T}=0.40 \mathrm{~ms}$

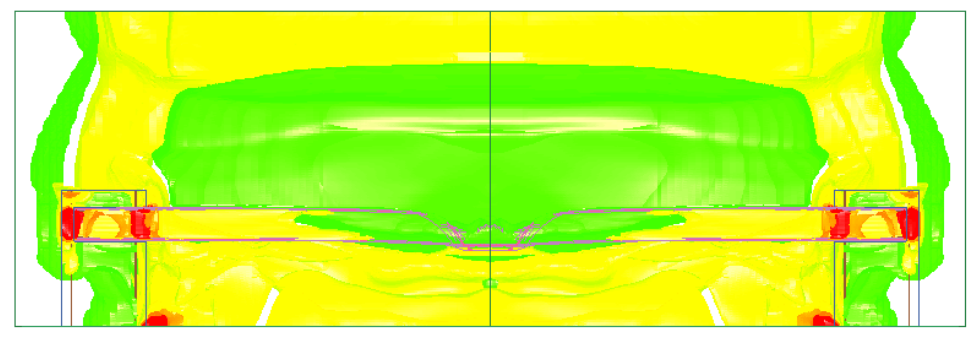

$\mathrm{T}=0.50 \mathrm{~ms}$

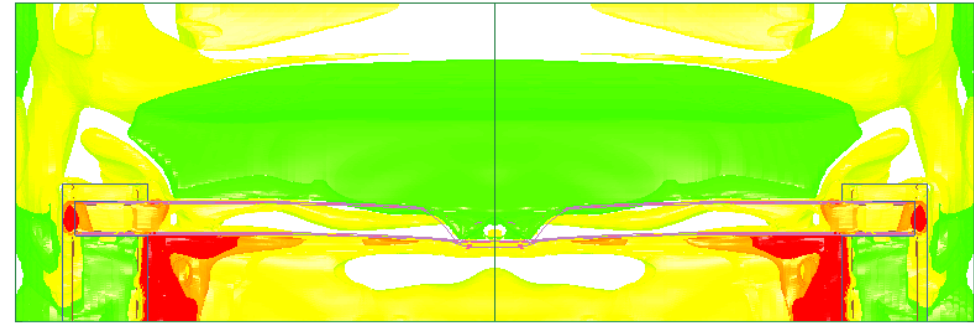

$\mathrm{T}=0.60 \mathrm{~ms}$

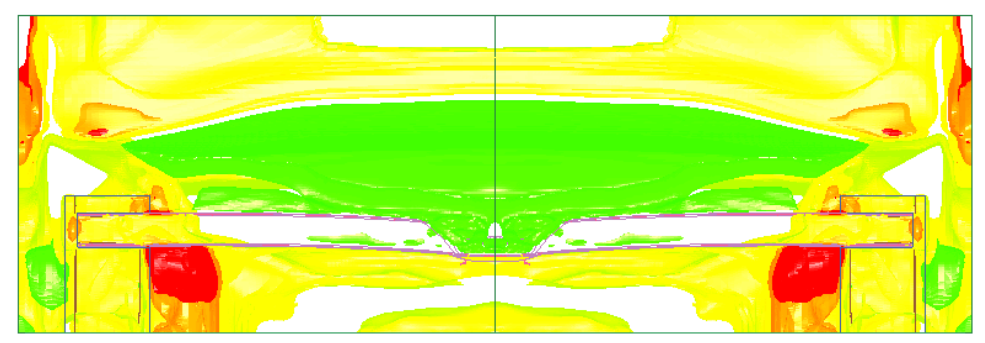

$\mathrm{T}=0.70 \mathrm{~ms}$

Figure 7. Blast pressure development during the initial phase of the explosion for configuration $\mathrm{C} 1$ 

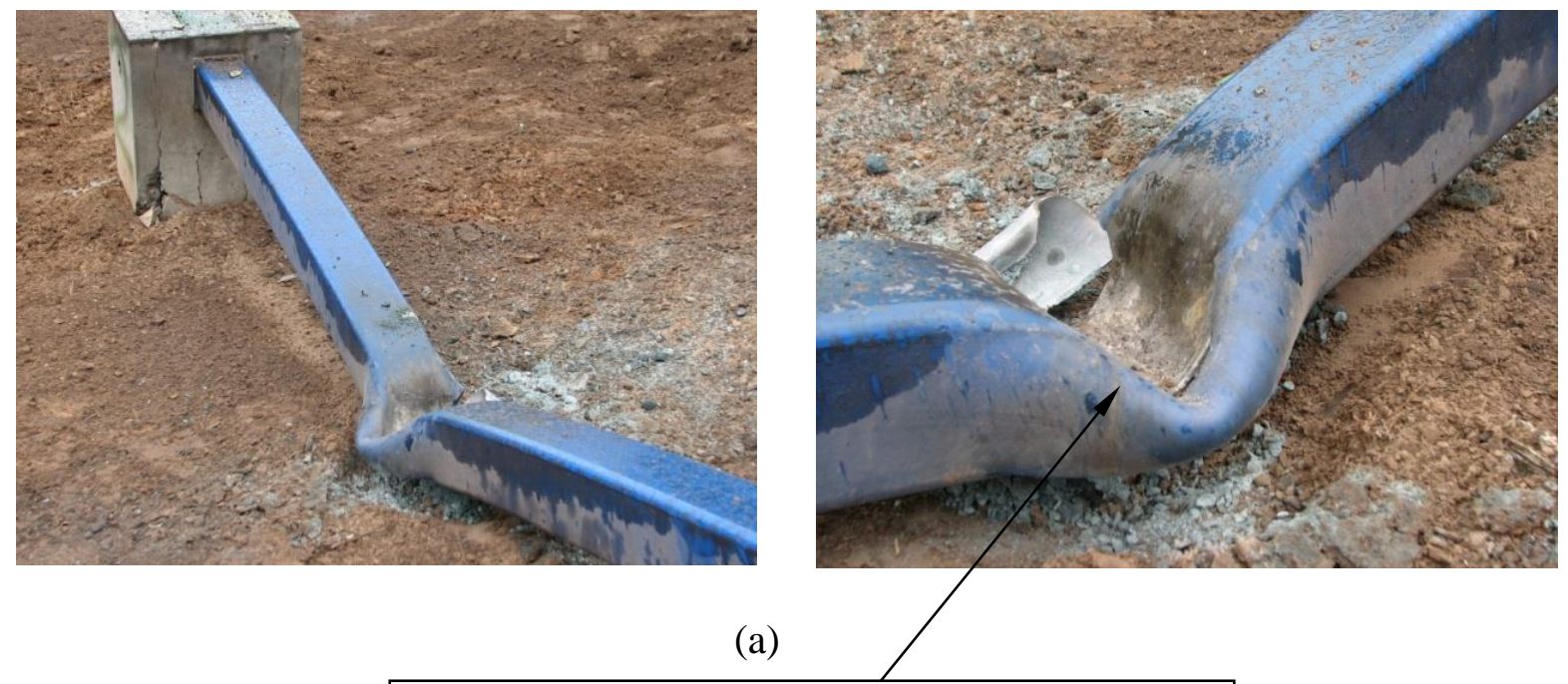

(a)

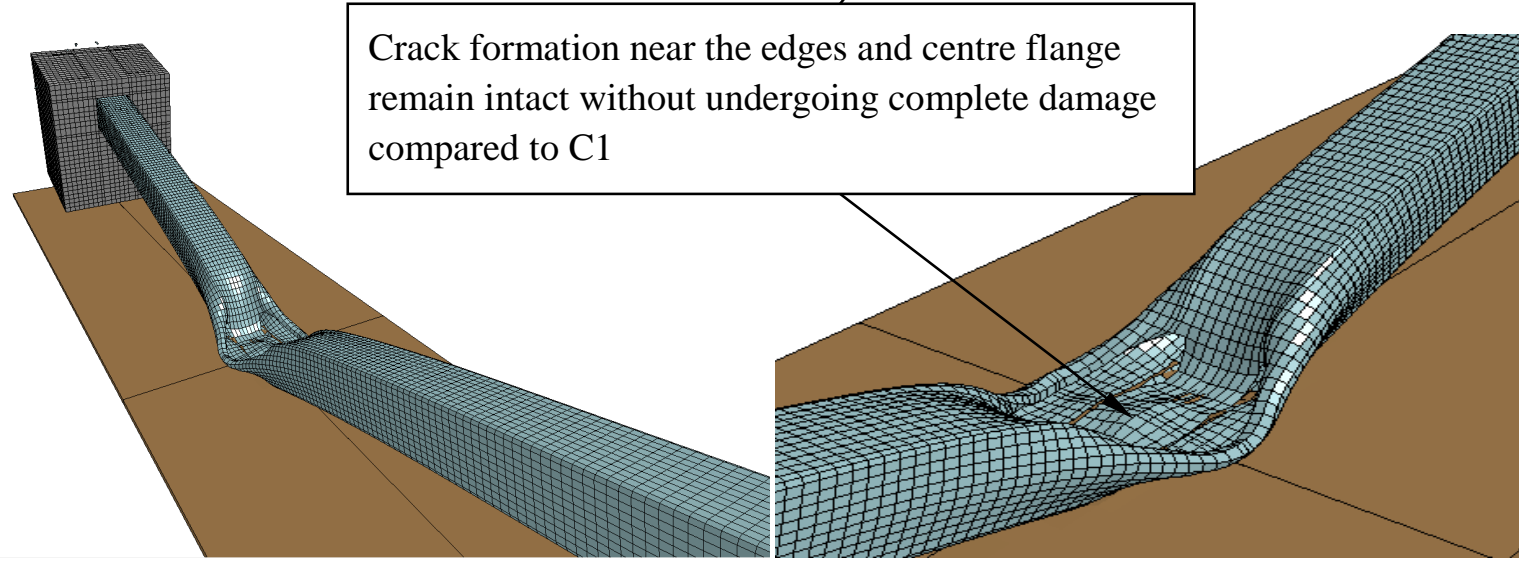

(b)

Figure 8. Local deformation history of concrete-filled SHS at mid-section (C2):

(a) Experimental results (b) Numerical simulation results (LS-DYNA) 


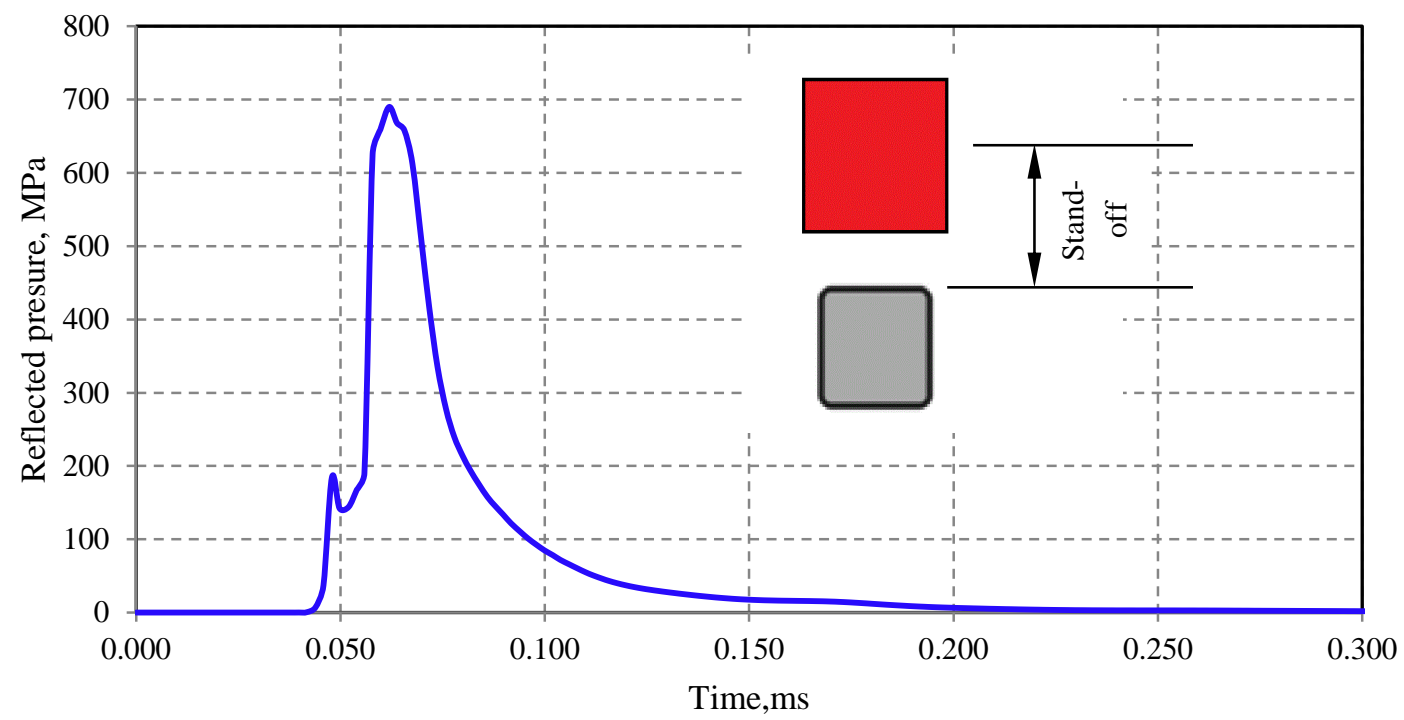

Figure 9. Pressure-time history at the top surface of the steel column for configuration C2

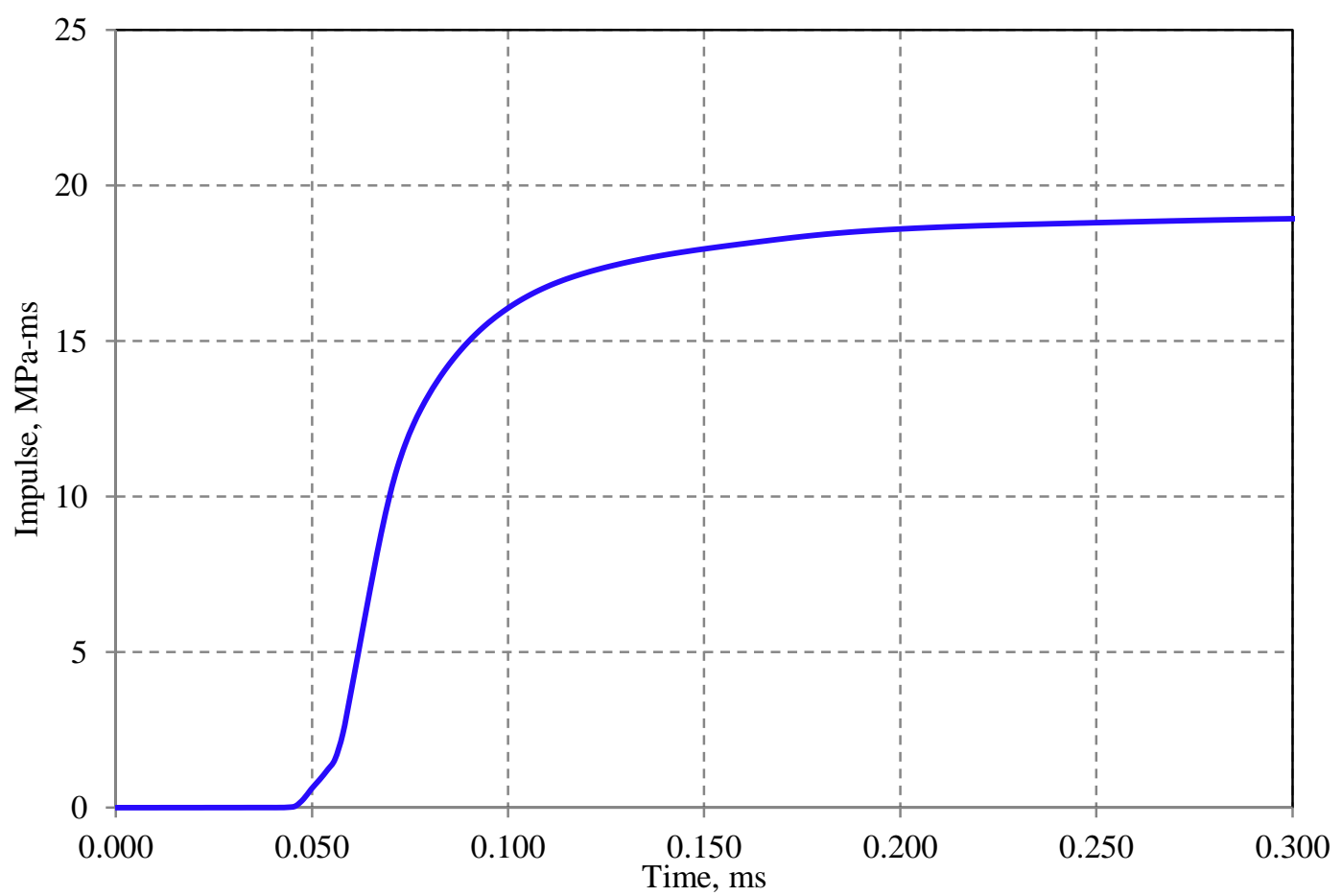

Figure 10. Impulse-time history at $220 \mathrm{~mm}$ from the detonation point for configuration $\mathrm{C} 2$ 


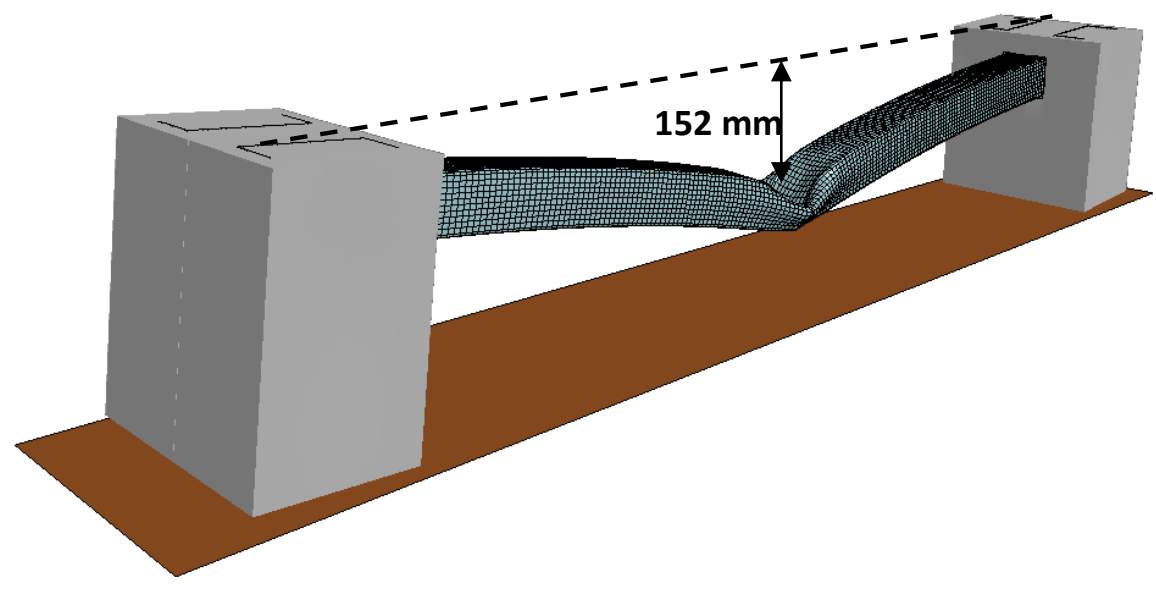

(a)
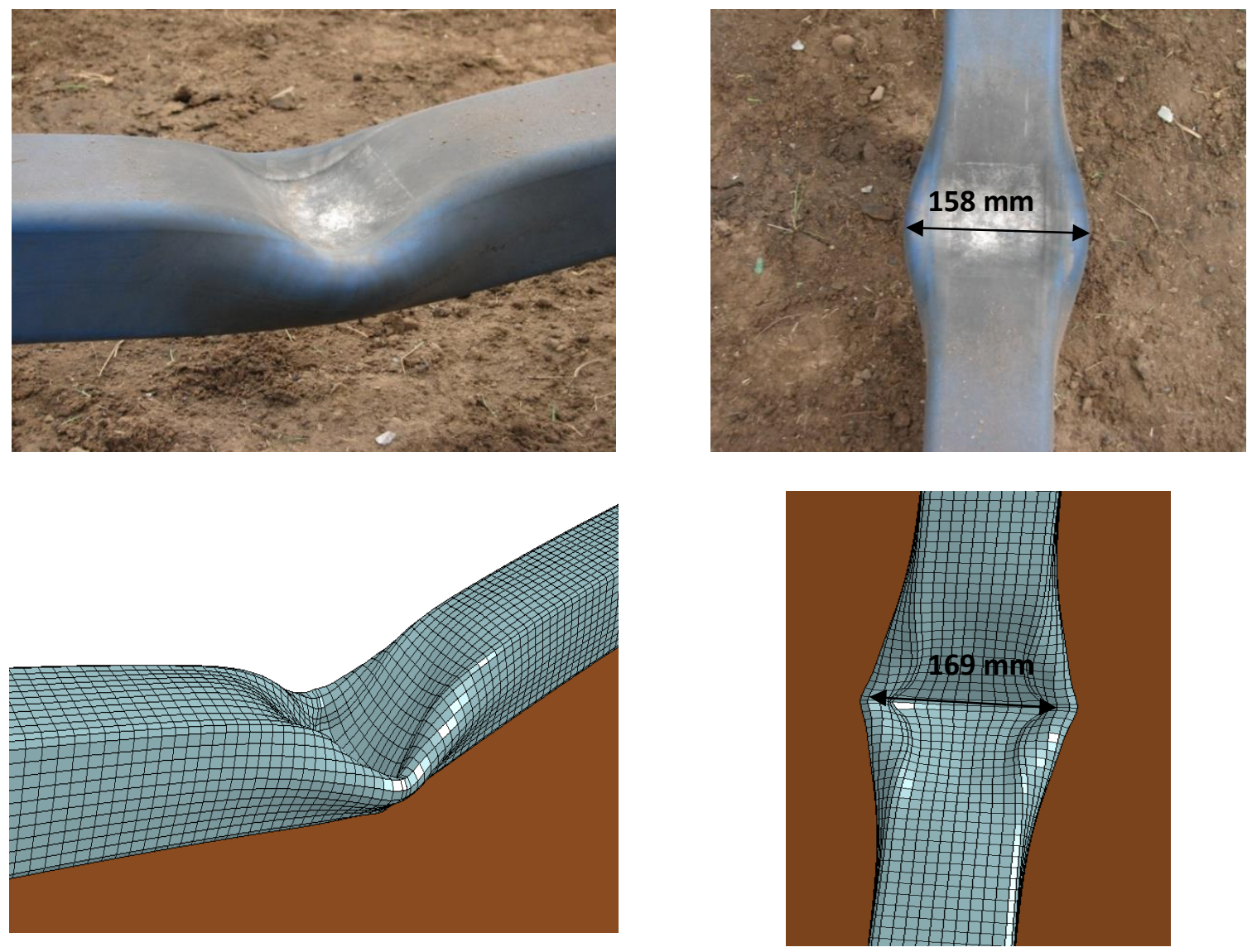

(b)

Figure 11. Comparison of deformation pattern for configuration C3: (a) Isometric view showing the global deformation, (b) Close-up view showing the local deformation 


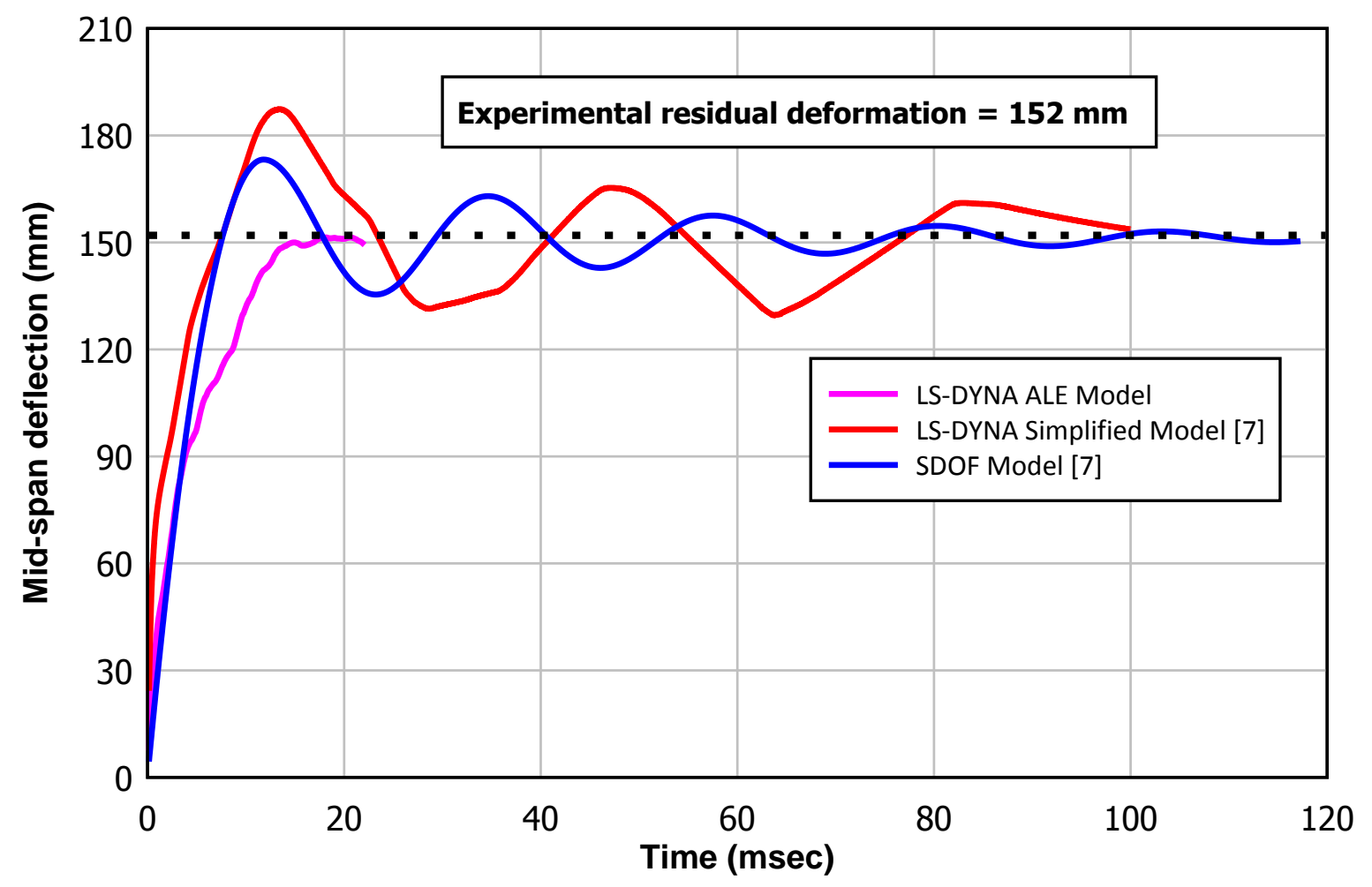

Figure 12. Deformation time history for configuration C3 


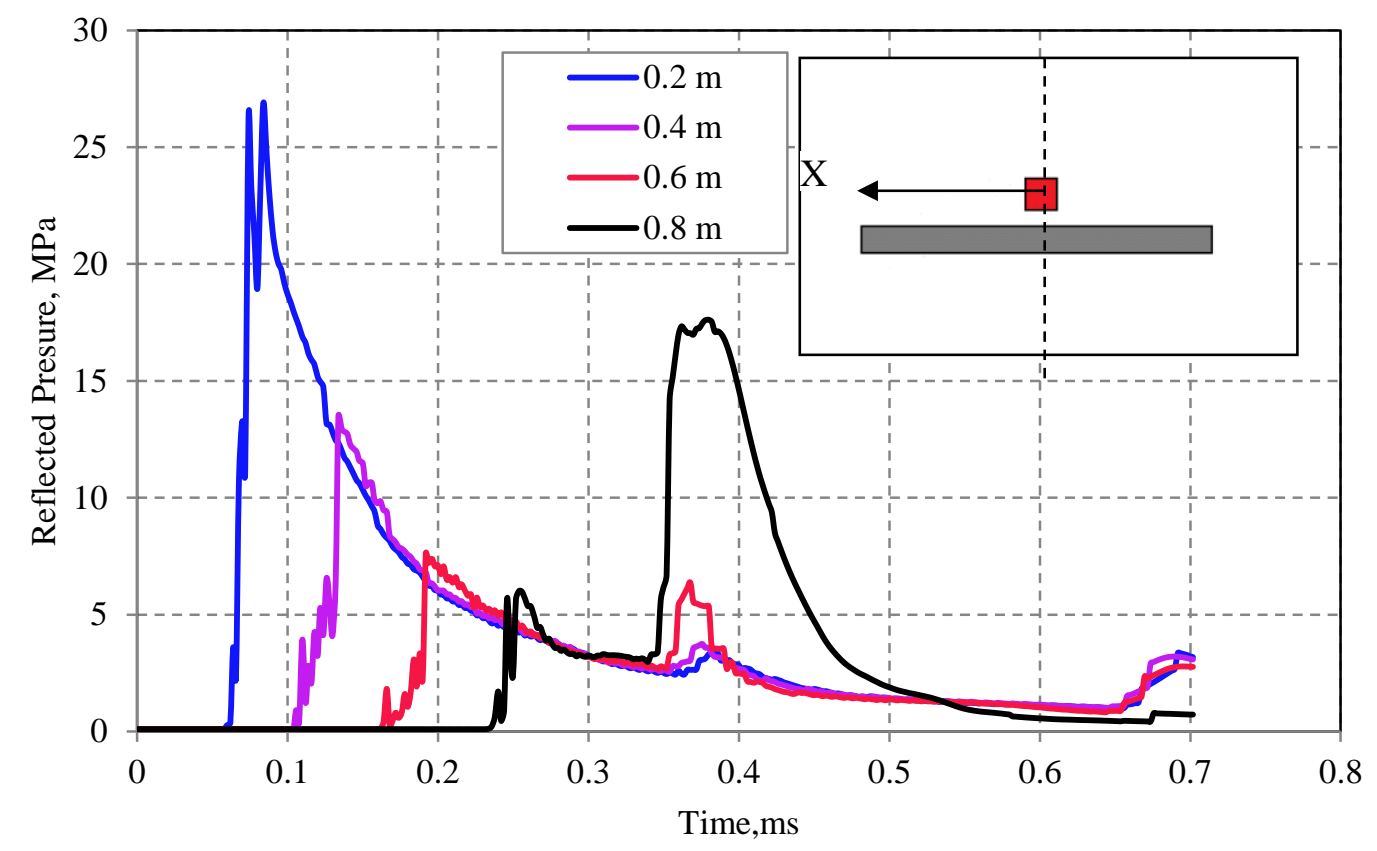

Figure 13. Pressure-time history along the top surface of the beam: distance measured from the symmetry line (Configuration C3)

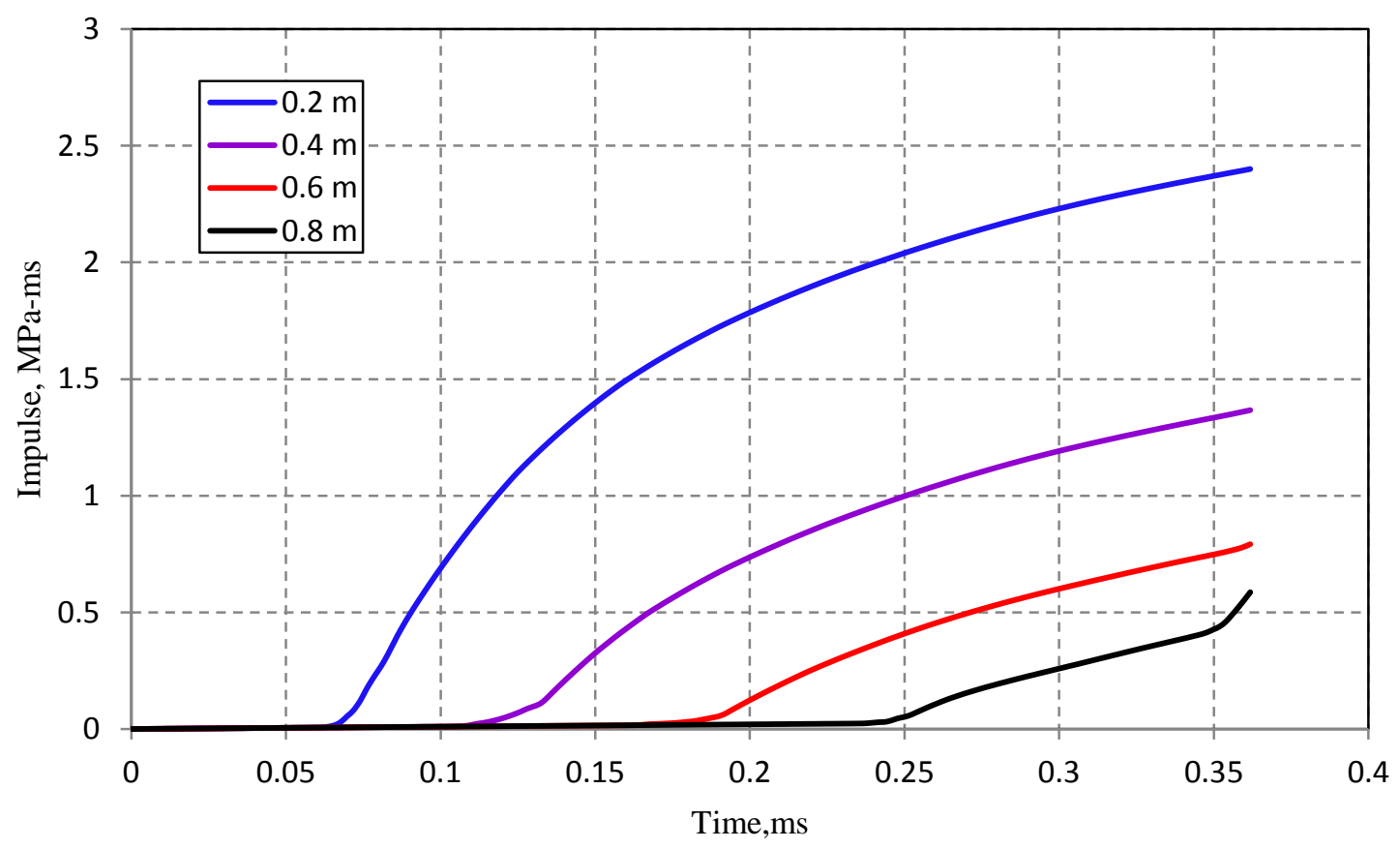


Figure 14. Impulse-time history along the top surface of the beam: distance measured from the symmetry line (Configuration C3)

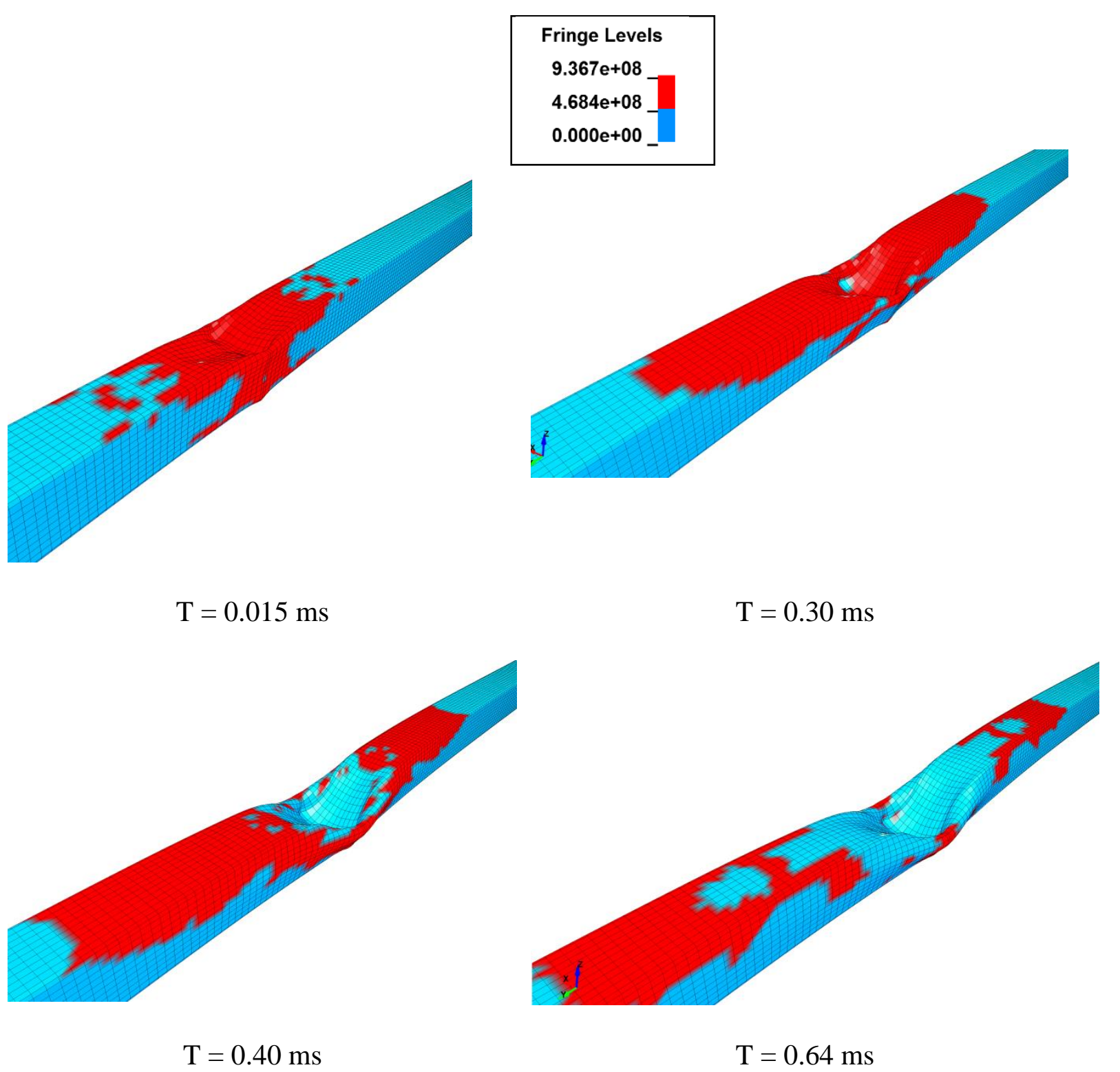

Figure 15. Von Mises stress contours captured during the local deformation phase for configuration $\mathrm{C} 3$ 

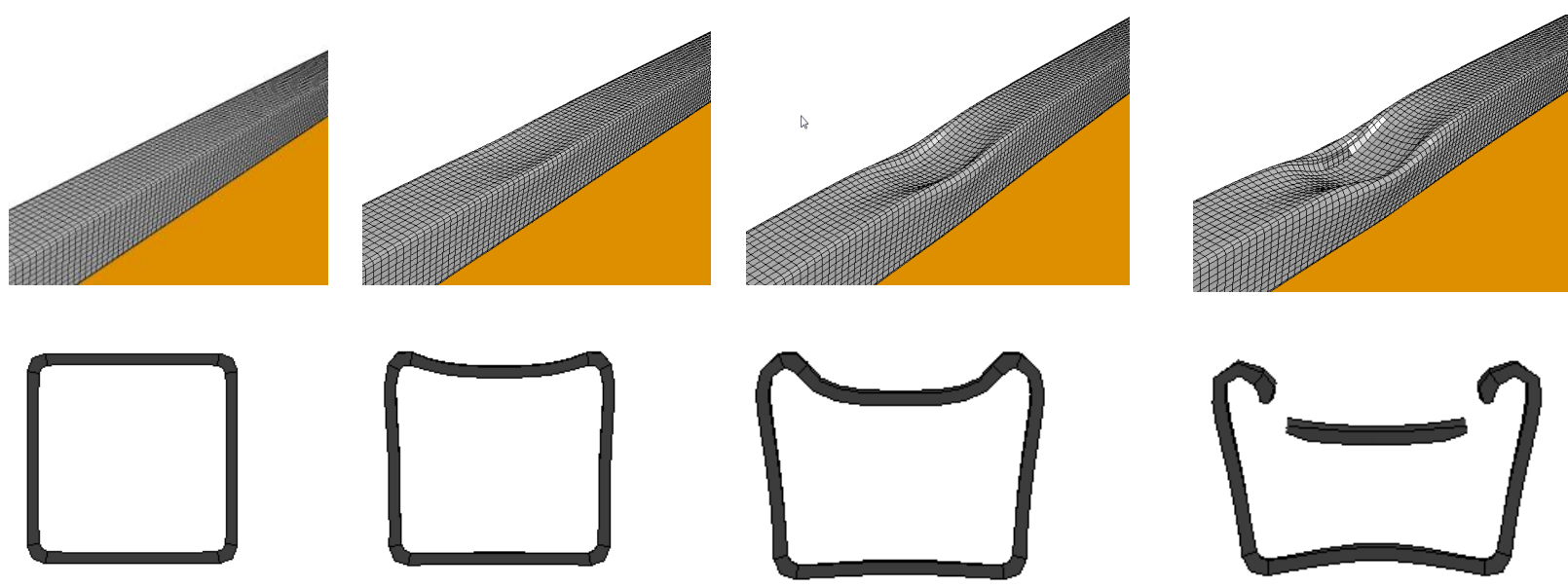

$\mathrm{T}=0$

$\mathrm{T}=0.1 \mathrm{~ms}$

$\mathrm{T}=0.14 \mathrm{~ms}$

$\mathrm{T}=0.18 \mathrm{~ms}$
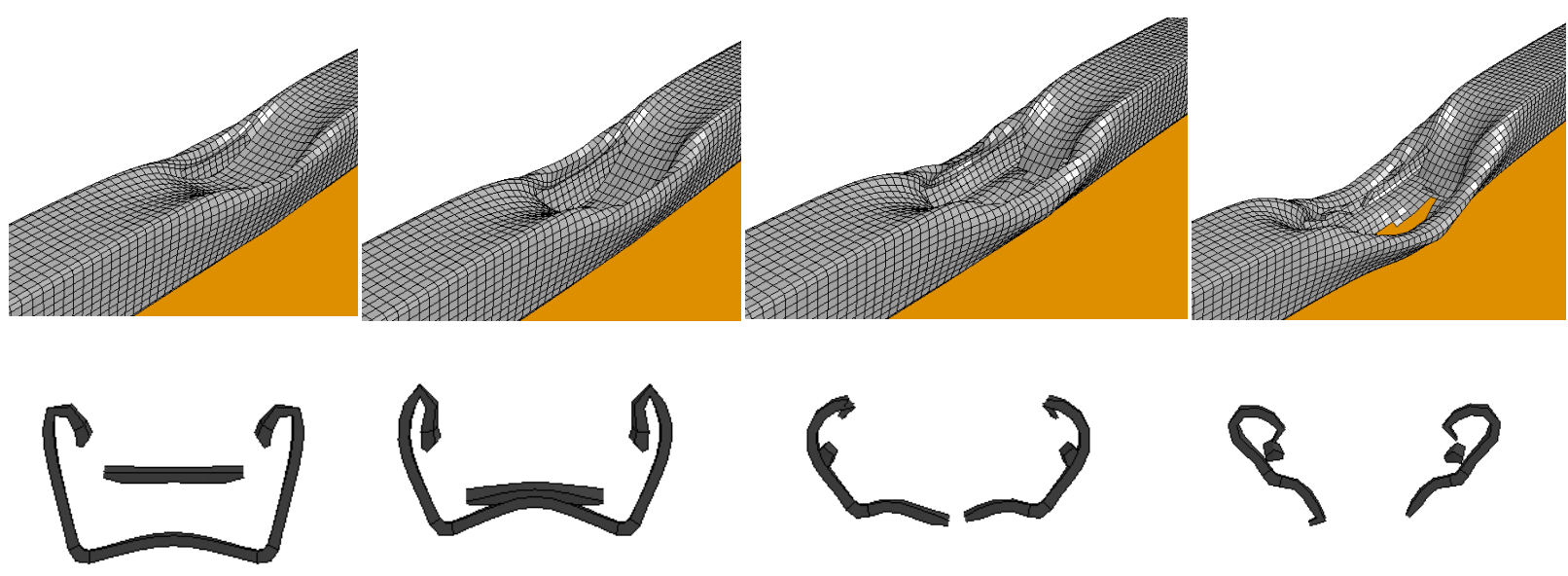

$\mathrm{T}=0.20 \mathrm{~ms}$

$\mathrm{T}=0.24 \mathrm{~ms}$

$\mathrm{T}=0.29 \mathrm{~ms}$

$\mathrm{T}=0.68 \mathrm{~ms}$

Figure 16. Local deformation of SHS tubular column at mid-section (C1) 

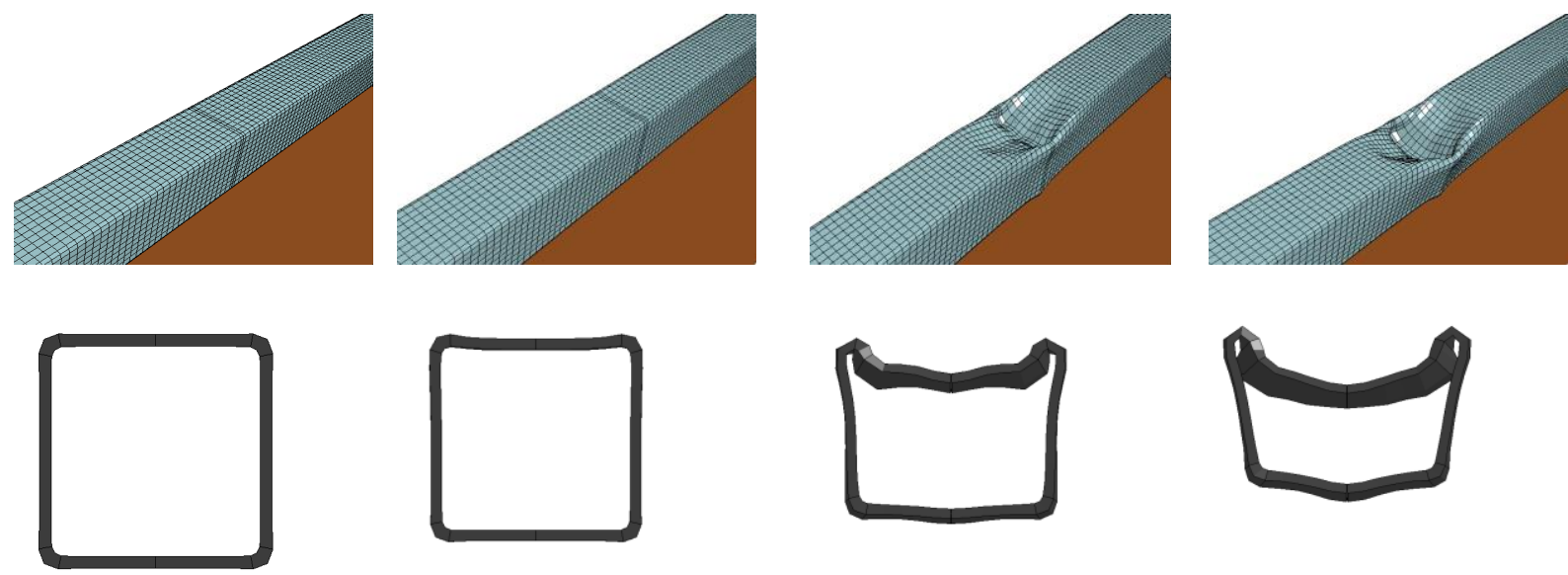

$\mathrm{T}=0$

$$
\mathrm{T}=0.08 \mathrm{~ms}
$$

$$
\mathrm{T}=0.16 \mathrm{~ms}
$$

$$
\mathrm{T}=0.22 \mathrm{~ms}
$$
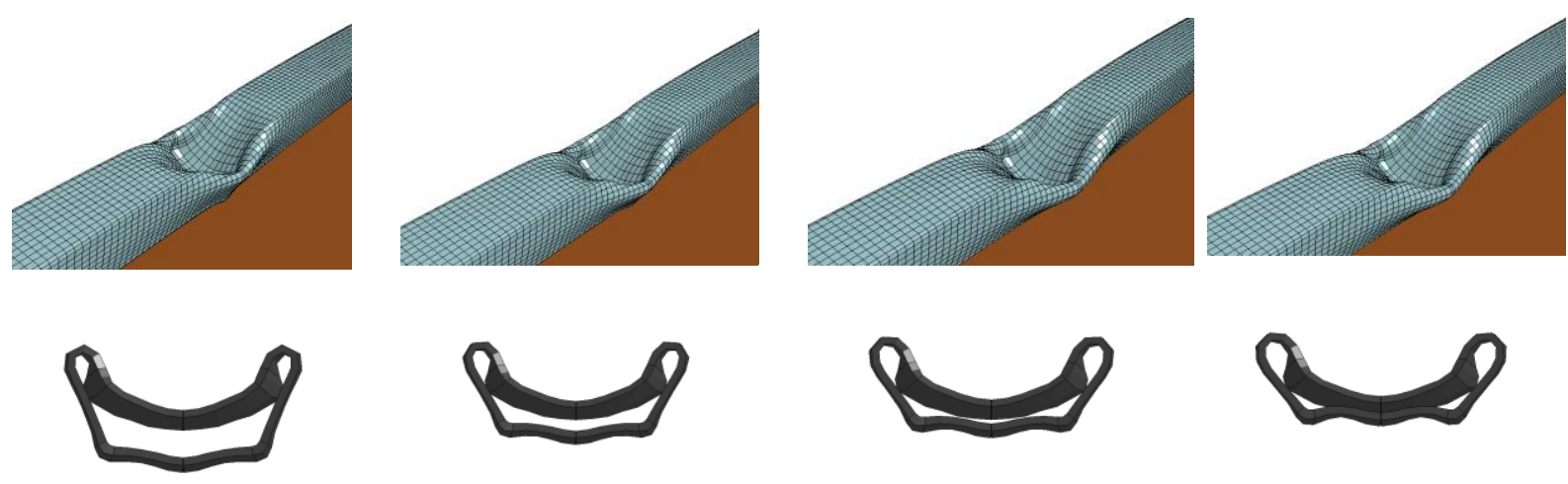

$\mathrm{T}=0.32 \mathrm{~ms}$

$\mathrm{T}=0.40 \mathrm{~ms}$

$\mathrm{T}=0.56 \mathrm{~ms}$

$\mathrm{T}=0.71 \mathrm{~ms}$

Figure 17. Local deformation of concrete-filled SHS at mid-section (C3) 


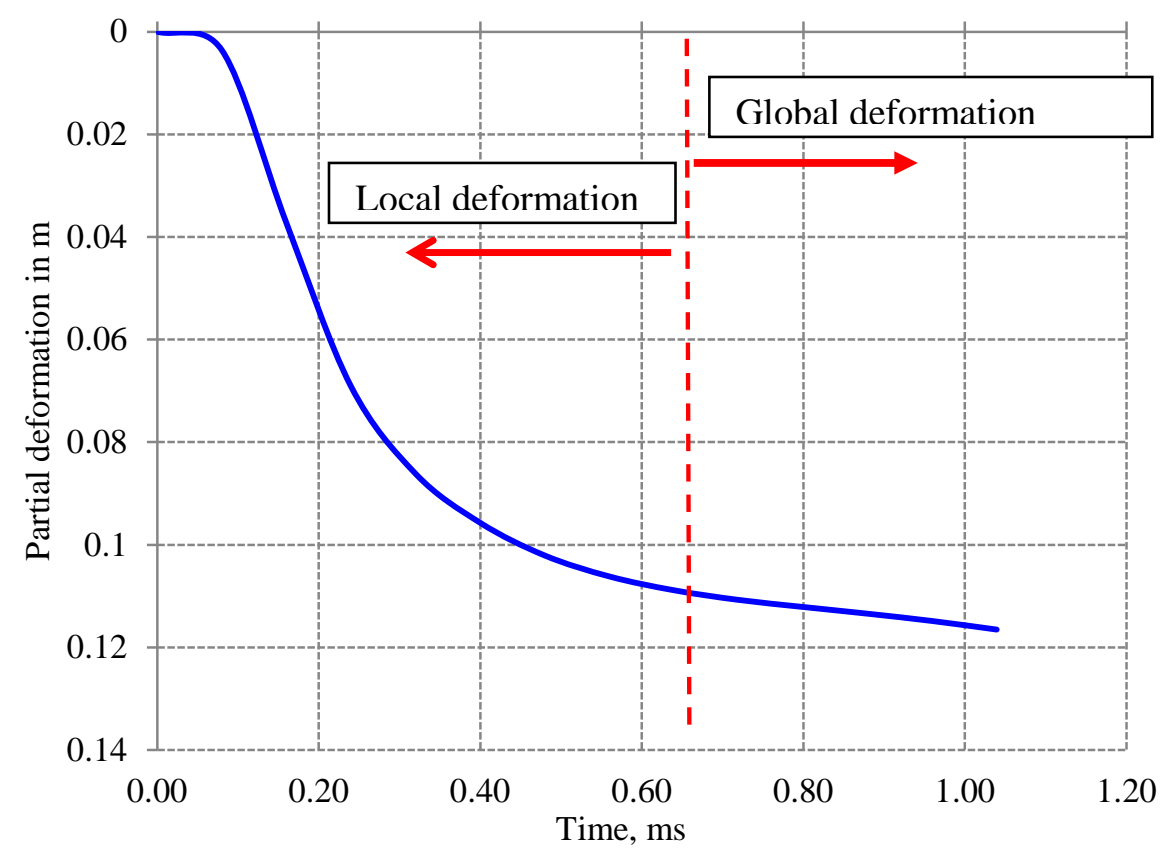

Figure 18. Local deformation history of concrete-filled SHS at mid-span of the beam (C3) partial extraction from Figure 12 


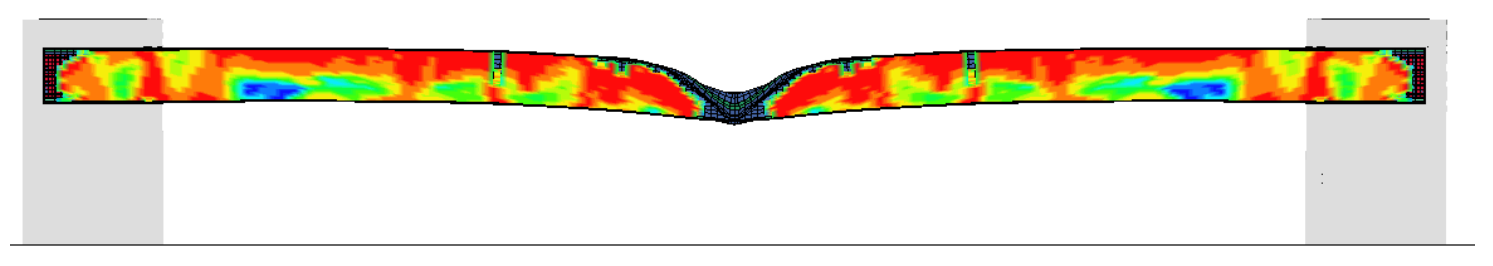

$$
\mathrm{T}=0.9 \mathrm{~ms}
$$

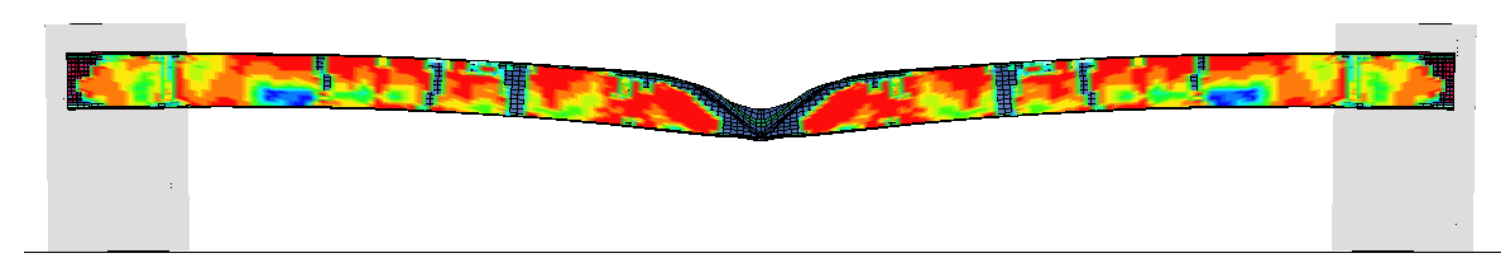

$$
\mathrm{T}=1.8 \mathrm{~ms}
$$

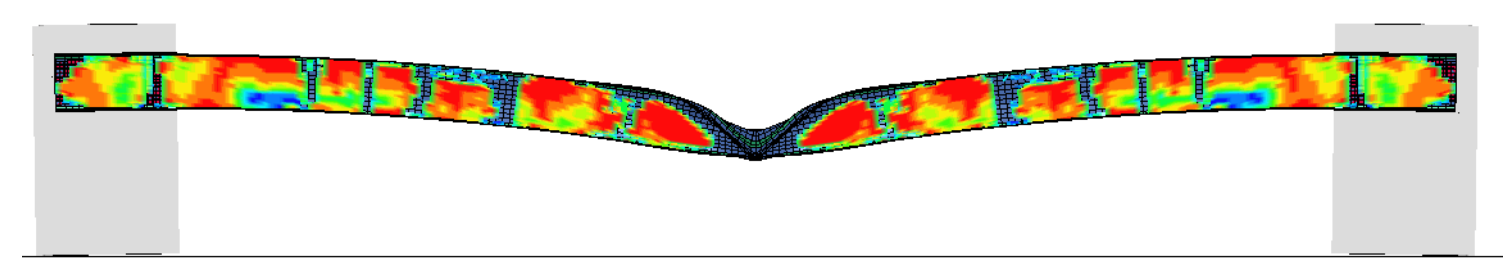

$$
\mathrm{T}=0.0035 \mathrm{~ms}
$$

Figure 19. Concrete crack formation and plastic strain contours 


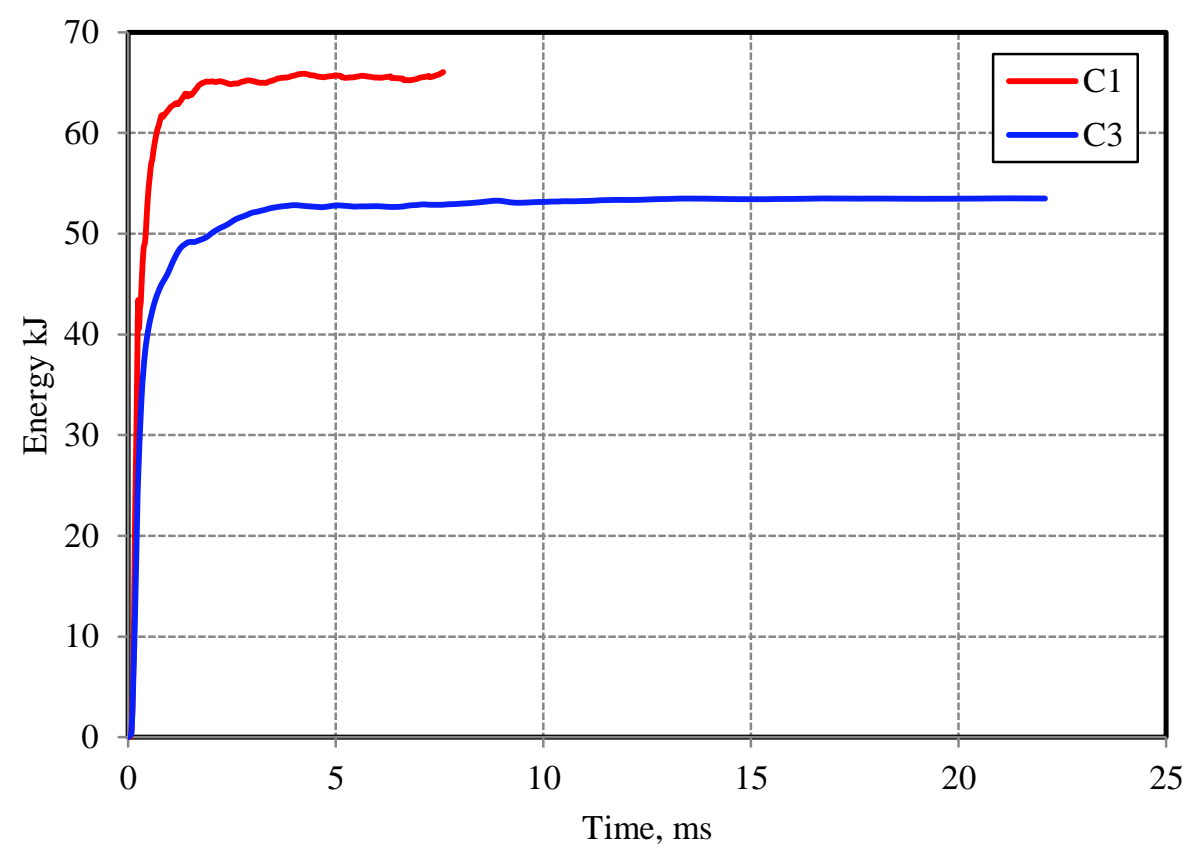

(a)

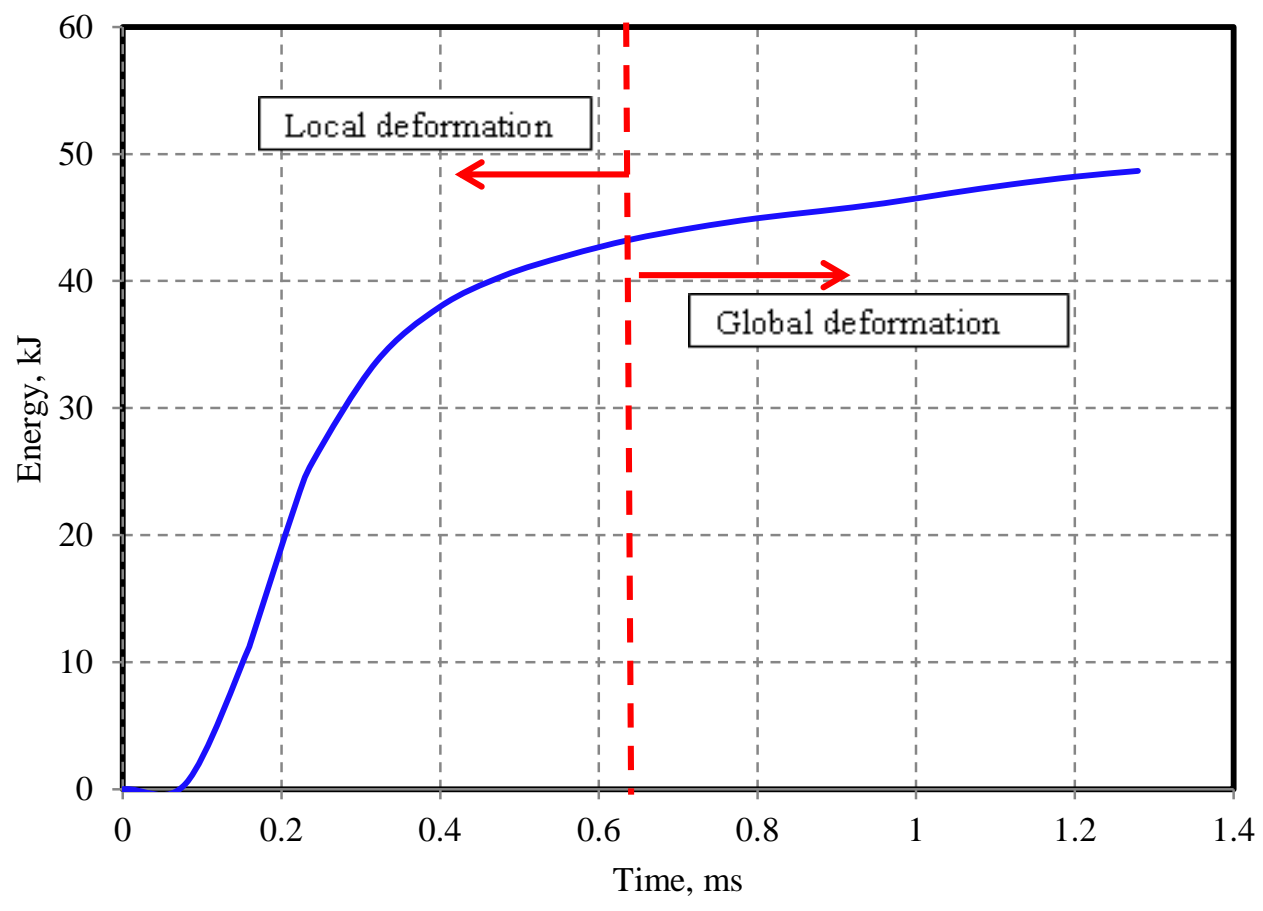

Figure 20. (a) Internal energy absorption history of configuration C1 (b) extracted portion of the energy absorption during localised deformation 